Article

\title{
The Highly Conducting Spin-Crossover Compound Combining Fe(III) Cation Complex with TCNQ in a Fractional Reduction State. Synthesis, Structure, Electric and Magnetic Properties
}

\author{
Yuri N. Shvachko ${ }^{1, *}$, Denis V. Starichenko ${ }^{1, *}$, Aleksander V. Korolyov ${ }^{1}$, Alexander I. Kotov ${ }^{2}$, \\ Lev I. Buravov ${ }^{2}$, Vladimir N. Zverev ${ }^{3,4}$, Sergey V. Simonov ${ }^{3}$, Leokadiya V. Zorina ${ }^{3, *}$ and \\ Eduard B. Yagubskii ${ }^{2, *}$ \\ 1 M.N. Miheev Institute of Metal Physics, Ural Branch of Russian Academy of Sciences, S. Kovalevskaya str., \\ 18, Yekaterinburg 620137, Russia; korolyov@imp.uran.ru \\ 2 Institute of Problems of Chemical Physics, Russian Academy of Sciences, Semenov ave., 1, Chernogolovka \\ 142432, Moscow Region, Russia; kotov@icp.ac.ru (A.I.K.); buravov@icp.ac.ru (L.I.B.) \\ 3 Institute of Solid State Physics, Russian Academy of Sciences, Ossipyan Street, 2, Chernogolovka 142432, \\ Moscow Region, Russia; zverev@issp.ac.ru (V.N.Z.); simonovsv@rambler.ru (S.V.S.) \\ 4 Department of General and Applied Physics, Moscow Institute of Physics and Technology, \\ Dolgoprudnyi 141700, Moscow Region, Russia \\ * Correspondence: yuri.shvachko@gmail.com (Y.N.S.); starichenko@imp.uran.ru (D.V.S.); \\ zorina@issp.ac.ru (L.V.Z.); yagubski@icp.ac.ru (E.B.Y.); Tel.: +74965228386 (Y.N.S. \& D.V.S. \& L.V.Z.); \\ +74965221185 (E.B.Y.)
}

Academic Editor: Manuel Almeida

Received: 23 January 2017; Accepted: 14 February 2017; Published: 22 February 2017

\begin{abstract}
Three systems [Fe(III)(sal ${ }_{2}$-trien)](TCNQ) $)_{n} \cdot \mathrm{X}\left(n=1,2, \mathrm{X}=\mathrm{MeOH}, \mathrm{CH}_{3} \mathrm{CN}, \mathrm{H}_{2} \mathrm{O}\right)$ showing spin-crossover transition, conductivity and ferromagnetic coupling were synthesized and studied by X-ray diffraction, Montgomery method for resistivity, SQUID magnetometry and X-band EPR. Spin-spin interactions between local magnetic moments of $\mathrm{Fe}(\mathrm{III})$ ions and electron spins of organic TCNQ network were discovered and discussed within the framework of intermolecular superexchange coupling.
\end{abstract}

Keywords: TCNQ radical anion salt; Fe(III) spin-crossover complex; crystal structure; conducting and magnetic properties

\section{Introduction}

The synthesis and investigation of multifunctional molecule materials combining conductivity and magnetism in the same crystal lattice attract considerable attention, because the interplay of these properties may lead to novel behavior [1-6]. Until recently, research in this direction has been focused on the family of the quasi-two-dimensional (super)conductors based on the radical cation salts of bis(ethylenedithio)tetrathiafulvalene (BEDT-TTF) and its derivatives with paramagnetic metal complex anions of different nature [2-6]. In such materials, conductivity is associated with mobile electrons in organic layers, whereas magnetism usually originates from localized spins of transition metal ions in insulating counterion layers. In particular, salts of BEDT-TTF and its selenium-substituted derivative bis(ethylenedithio)tetraselenafulvalene (BETS) have been shown to combine (super)conducting and paramagnetic [7-10] and even antiferromagnetic [11,12] and ferromagnetic properties [13]. Moreover, interaction between localized spins in insulating magnetic layers and itinerant spins in conducting organic layers was found to lead to new fascinating phenomena such as field-induced superconductivity observed on $\lambda$-(BETS $)_{2} \mathrm{FeCl}_{4}[14]$ and $\mathrm{k}-(\mathrm{BETS})_{2} \mathrm{FeBr}_{4}$ [15]. 
In the last decade, a new trend in choosing of magnetic subsystems for design of multifunctional materials combining conductivity and magnetism was outlined. The trend is associated with the use of the octahedral cation complexes of $\mathrm{Fe}(\mathrm{II}), \mathrm{Fe}(\mathrm{III})$ and $\mathrm{Co}(\mathrm{II})$, showing reversible spin-crossover (SCO) between high-spin (HS) and low-spin (LS) states of the metal ion, in combination with the radical anion conducting subsystems $[16,17]$. The latter could be represented by the systems based on $\left[M(\mathrm{dmit})_{2}\right]^{\delta-}$ complexes $(M=\mathrm{Ni}$, Pd, Pt; dmit $=4,5$-dithiolato-1,3-dithiole-2-thione; $0<\delta<1)$ [18] and/or 7,7,8,8,-tetracyanoquinodimethane $\left((\mathrm{TCNQ})^{\delta-}, 0<\delta<1\right)$ [19-23]. The availability of fractional oxidation $\left(\left[M(\mathrm{dmit})_{2}\right]^{\delta-}\right)$ or reduction states $\left((\mathrm{TCNQ})^{\delta-}\right)$ is a necessary condition for the emergence of high conductivity in these systems. The SCO induced by temperature, pressure or light irradiation is accompanied by the changes in the coordination environment of the metal ion [24-26]. The electrical conductivity of the most molecular conductors is very sensitive to external and/or chemical pressure $[27,28]$. There is an every reason to believe that spin-crossover transition would affect the conductivity at least via a chemical compression or extension arising from structural perturbations in the process of SCO. Furthermore, magnetic interactions between the subsystems make possible a realization of a spin-dependent electronic transport. The interplay between spin-crossover and conductivity was already observed in some of such materials [17,29-33]. The most of conducting SCO compounds represent the Fe(III) cation complexes with $\left[M(\mathrm{dmit})_{2}\right]^{\delta-}$ anions $[29,30,34-38]$. There is only one compound with $\mathrm{TCNQ}^{\delta-}$, described in publications: [Fe(III)(acpa $\left.)_{2}\right](\mathrm{TCNQ})_{2}$, with $\sigma_{\mathrm{rt}}=2.810^{-3} \Omega^{-1} \cdot \mathrm{cm}^{-1}$ [39]. The crystal structure of the latter has not been solved. Recently, four spin-crossover compounds, combining $\mathrm{Fe}(\mathrm{II})$ and $\mathrm{Co}(\mathrm{II})$ cation complexes with $\mathrm{TCNQ}^{\delta-}$ anions, have been obtained $[32,33,40]$ and showed the conductivity in the range of $10^{-2}-10^{-1} \Omega^{-1} \cdot \mathrm{cm}^{-1}$.

In this paper, we report synthesis, structure, and physical properties of the three new spin-crossover compounds based on the $\mathrm{Fe}(\mathrm{III})$ cationic complex, $\left[\mathrm{Fe}\left(\mathrm{sal}_{2} \text {-trien) }\right]^{+}\left(\mathrm{H}_{2} \mathrm{Sal}_{2}\right.\right.$-trien $=N, N^{\prime}$-bis[2-(salicylideneamino)ethyl]ethane-1,2-diamine), with TCNQ counterions in a fraction and fully reduced states, [Fe(III)( sal $_{2}$-trien)](TCNQ) $)_{2} \cdot \mathrm{CH}_{3} \mathrm{OH}(\mathbf{1} \cdot \mathrm{MeOH}), \quad\left[\mathrm{Fe}(\mathrm{III})\left(\mathrm{sal}_{2}\right.\right.$-trien)] (TCNQ) $\cdot \mathrm{CH}_{3} \mathrm{CN}$ (2) and [Fe(III)( $\left(\mathrm{sal}_{2}\right.$-trien)](TCNQ) $\cdot \mathrm{H}_{2} \mathrm{O}$ (3). The compound $\mathbf{1} \cdot \mathrm{MeOH}$ possesses a record conductivity $\left(5.0-6.0 \Omega^{-1} \cdot \mathrm{cm}^{-1}\right)$ among known conducting SCO-compounds, whereas the magnetic response of the low conducting 2 and $\mathbf{3}$ demonstrate a hysteresis and a phase fractionation. A residual high-spin phase in $\mathbf{2}$ demonstrates a ferro(ferri)magnetic coupling at helium temperatures. Local magnetic moments in all three systems reveal spin-spin interactions in the SCO range.

\section{Results and Discussion}

\subsection{Synthesis}

The compound [ $\mathrm{Fe}(\mathrm{III})\left(\mathrm{sal}_{2} \text {-trien)](TCNQ) }\right)_{2} \cdot \mathrm{CH}_{3} \mathrm{OH}(\mathbf{1} \cdot \mathrm{MeOH})$ were obtained by mixing $\mathrm{CH}_{3} \mathrm{CN}$ solution of TCNQ with the solutions of [Fe(III)(sal 2 -trien)] $\cdot 1.5 \mathrm{H}_{2} \mathrm{O}$ and LiTCNQ in a mixture of acetonitrile/methanol (see Materials and Methods). The resulting solution was left to stand in a refrigerator overnight. The black plate crystals of $\mathbf{1} \cdot \mathrm{MeOH}$ were formed (Figure S1). Figure S2 displays the thermogram of $\mathbf{1} \cdot \mathrm{MeOH}$. With increasing temperature, a weight loss of $4.43 \%$ was observed in the temperature range $70-150{ }^{\circ} \mathrm{C}$ with endothermic peak at $126.7^{\circ} \mathrm{C}$, which is assigned to the loss of crystallization methanol molecule (calc. 3.77\%). As this takes place, the ions with $\mathrm{m} / \mathrm{e} 29$ (CHO) and $31\left(\mathrm{CH}_{3} \mathrm{O}\right)$ relating to the fragments of methanol molecule are observed in the mass spectrum. On heating above $200{ }^{\circ} \mathrm{C}$, the complex begins to decompose (two DSC-peaks at 210.1 and $222.6^{\circ} \mathrm{C}$ ).

The compound $\left[\mathrm{Fe}(\mathrm{III})\left(\mathrm{sal}_{2}\right.\right.$-trien)](TCNQ) $\cdot \mathrm{H}_{2} \mathrm{O}$ (3) in the polycrystalline form was prepared by metathesis reaction between $\left[\mathrm{Fe}(\mathrm{III})\left(\mathrm{sal}_{2}\right.\right.$-trien)] $\mathrm{I} \cdot 1.5 \mathrm{H}_{2} \mathrm{O}$ and $\mathrm{Li}(\mathrm{TCNQ})$ in methanol. The recrystallization of 3 from acetonitrile yielded the crystals of [ $\mathrm{Fe}(\mathrm{III})\left(\mathrm{sal}_{2}\right.$-trien)](TCNQ) $\cdot \mathrm{CH}_{3} \mathrm{CN}$ (2) (Materials and Methods). The thermogram of 2 demonstrates a mass loss of $6.38 \%$ in the temperature range $70-100{ }^{\circ} \mathrm{C}$ with endothermic peak at $93^{\circ} \mathrm{C}$, which corresponds to the loss of lattice acetonitrile molecule (calc. $6.27 \%$ ). (Figure S3). In the mass spectrum recorded in the gas phase, the peaks are observed at $m / z 41,15$ and 26 relating to $\mathrm{CH}_{3} \mathrm{CN}$ molecular ion and the fragments of acetonitrile 
molecule $\left(\mathrm{CH}_{3}: m / z=15 ; \mathrm{CN}: m / z=26\right)$. The decomposition of 2 starts above $200{ }^{\circ} \mathrm{C}$ (two DSC-peaks at 227.1 and $\left.232.0^{\circ} \mathrm{C}\right)$ and accompanies by the release of $\mathrm{CN}$-fragments $(m / z=26)$.

\subsection{Crystal Structure}

\subsection{1. $\left[\mathrm{Fe}(\mathrm{III})\left(\mathrm{sal}_{2}\right.\right.$-trien $\left.)\right](\mathrm{TCNQ})_{2} \cdot \mathrm{CH}_{3} \mathrm{OH}(\mathbf{1} \cdot \mathrm{MeOH})$}

The structure of $\mathbf{1} \cdot \mathrm{MeOH}$ has been investigated at several different temperatures between 100 and $385 \mathrm{~K}$. The asymmetric unit of the triclinic $P \overline{1}$ unit cell of initial $\mathbf{1} \cdot \mathrm{MeOH}$ crystal includes two independent $\mathrm{TCNQ}^{\bullet-}$ - radical anions (denoted as I and II), one $\left[\mathrm{Fe}\left(\mathrm{sal}_{2} \text {-trien) }\right]^{+}\right.$cation and one methanol molecule in general positions (Figure 1). The crystal structure consists of layers of TCNQ radical anions parallel to the $a b$-plane which alternate with mixed $\mathrm{Fe}\left(\mathrm{sal}_{2}\right.$-trien)-solvent layers along the $c$-axis (Figure 2).

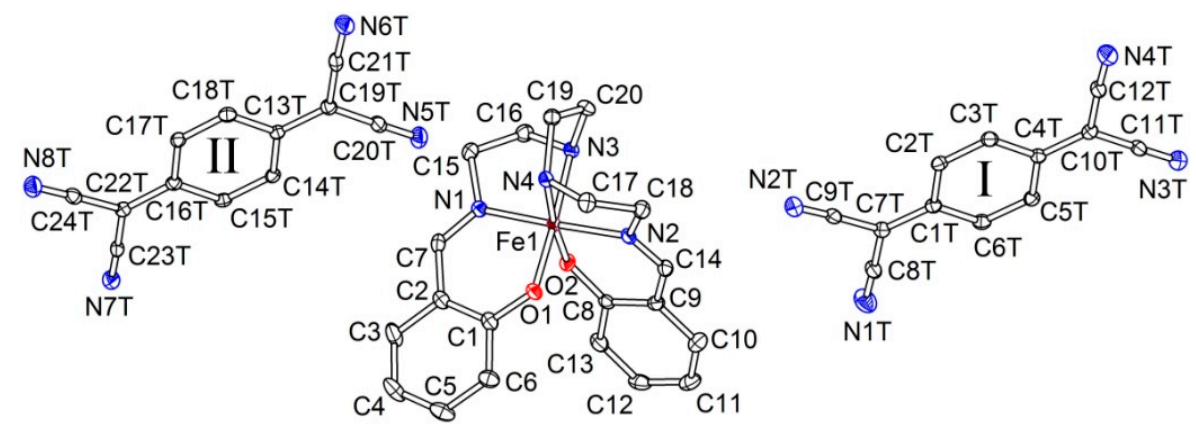

Figure 1. Asymmetric unit in $1 \cdot \mathrm{MeOH}$ (ORTEP drawing with $50 \%$ probability ellipsoids, solvent molecule is omitted).

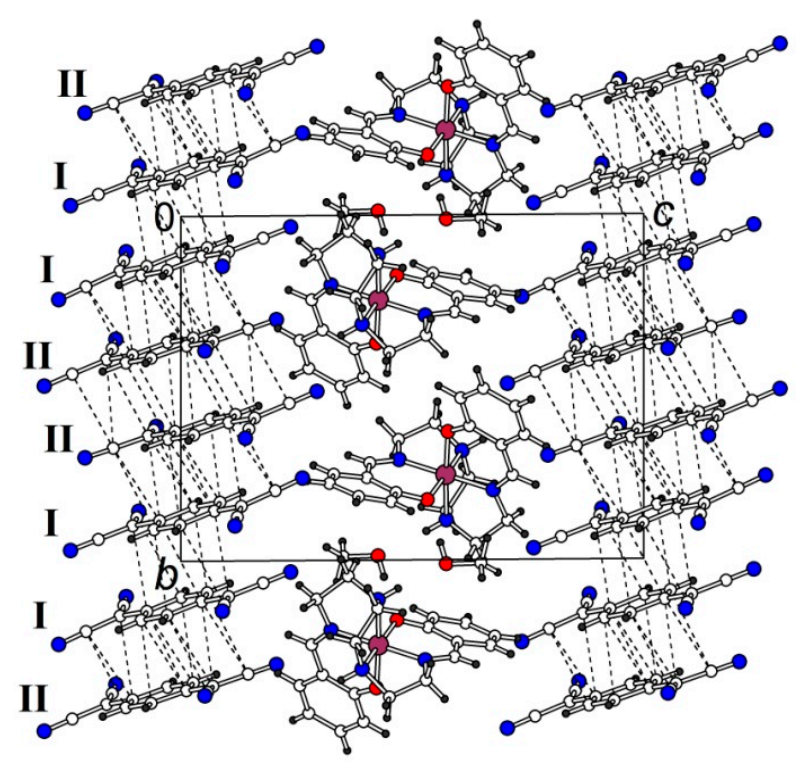

Figure 2. View of the structure $1 \cdot \mathrm{MeOHat} 100 \mathrm{~K}$ along $a$. Intrastack $\mathrm{C}$... C contacts $(<3.4 \AA)$ are shown by dashed lines.

In the $100 \mathrm{~K}$ structure, charge state of both independent $\mathrm{TCNQ}^{\bullet-}-$ radical anions I and II is slightly different and close to -0.4 and -0.6 , respectively, according to calculations on the base of intramolecular bond lengths using Kistenmacher's empirical formula [41] (Table S1). $\pi$-stacking of TCNQ anions leads to a formation of infinite stacks along the [11 0$]$ direction. The stacks are composed of tetrads ... -(II-I-I-II)-(II-I-I-II)-... (Figure 2) with ring-over-bond overlap inside the tetrad due to 
longitudinal shift of adjacent anions and ring-over-ring one between the tetrads (longitudinal shift is absent, Figure S4). Interplane separations in the stack at $100 \mathrm{~K}$ are 3.274(4) $\AA$ (I. . . I), 3.19(4) $\AA$ (I. . II) and 3.297(6) $\AA$ (II. . II), the angle between mean planes of I and II is 2.37(5) . There are a lot of intrastack C. . C contacts shorter than $3.4 \AA$, while adjacent stacks interact only by weak hydrogen contacts of C-H. . . N type with H. . . N distances of 2.58-2.73 $\AA$.

The $\left[\mathrm{Fe}(\mathrm{III})\left(\mathrm{sal}_{2} \text {-trien) }\right]^{+}\right.$cations are located between the TCNQ layers and connected by hydrogen contacts with surrounding TCNQ and methanol molecules. The Fe(III) ion has a slightly distorted octahedral coordination geometry formed by two oxygen and four nitrogen atoms of ligand. Key bond distances and angles in the $\mathrm{Fe}(\mathrm{III})\left(\mathrm{sal}_{2}\right.$-trien) ${ }^{+}$cation at $100 \mathrm{~K}$ are listed in Table S2. Mean values of the $\mathrm{Fe}-\mathrm{O}, \mathrm{Fe}-\mathrm{N}_{\text {imine }}$ and $\mathrm{Fe}-\mathrm{N}_{\text {amine }}$ bond distances in the $\mathrm{FeN}_{4} \mathrm{O}_{2}$ chromophore (1.885(8), 1.936(8) and 2.007(2) $\AA$, respectively) and shape of the cation with the dihedral angle $\alpha$ between two phenoxy groups of 53.87(6) ${ }^{\circ}$ (Figure 3a) correspond to the low-spin state of the Fe(III) ion. The diagonals of the octahedron at $\mathrm{Fe}$ centre are close to linear $\left(\mathrm{N}-\mathrm{Fe}-\mathrm{O}\right.$ and $\mathrm{N}-\mathrm{Fe}-\mathrm{N}$ angles are $174^{\circ}-177^{\circ}$, Table S2) that is also characteristic for the LS state. The coordination $\mathrm{FeN}_{4} \mathrm{O}_{2}$ octahedrons are much more regular in LS state than in HS one [24-26,34]. There is no $\pi$-stacking between phenolate ligands of the nearest cations. Most of the cation-anion hydrogen contacts are formed with TCNQ II that is in agreement with higher charge of the latter in comparison with TCNQ I. There are two N- $\mathrm{H}_{\text {cat }} \ldots \mathrm{N}_{\text {II }}$ contacts with $\mathrm{H} . . \mathrm{N}$ distances of 2.35 and $2.52 \AA$ and three $\mathrm{C}-\mathrm{H}_{\text {cat }} \ldots \mathrm{N}_{\mathrm{II}}$ contacts with $\mathrm{H} \ldots \mathrm{N}=2.44,2.53$ and $2.65 \AA$ and only two C-H. . N N contacts to TCNQ I with longer H. . N distances of 2.69 and $2.73 \AA$. The $\left[\mathrm{Fe}(\mathrm{III})\left(\mathrm{sal}_{2} \text {-trien) }\right]^{+}\right.$cations are also hydrogen bonded to the methanol solvent molecules $\left(\mathrm{N}-\mathrm{H}_{\text {cat }} \ldots \mathrm{O}_{\text {solv }}, \mathrm{C}-\mathrm{H}_{\text {cat }} \ldots \mathrm{O}_{\text {solv }}\right.$ and $\mathrm{O}_{\text {cat }} \ldots \mathrm{H}-\mathrm{O}_{\text {solv }}$ contacts with $\mathrm{H} . . \mathrm{O}$ distances of 2.04, 2.46 and $1.80 \AA$, respectively).
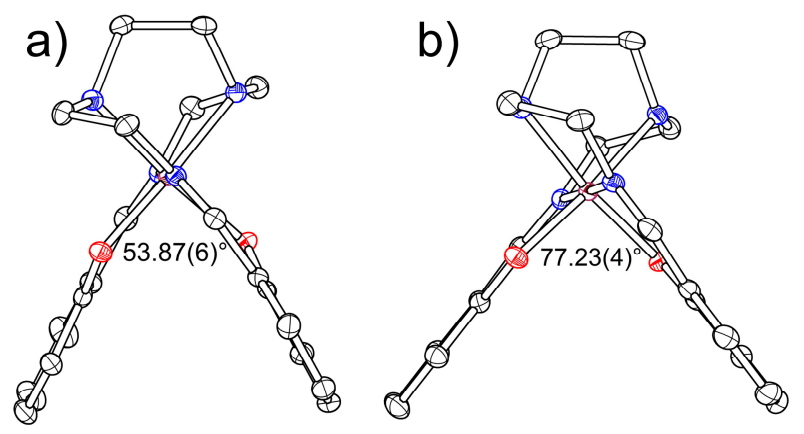

Figure 3. Molecular conformation of the $\left[\mathrm{Fe}(\mathrm{III})\left(\mathrm{sal}_{2} \text {-trien) }\right]^{+}\right.$cation at $100 \mathrm{~K}$ in $\mathbf{1} \cdot \mathrm{MeOH}(\mathbf{a})$ and 2 (b).

In order to follow the spin-crossover transition in the crystal of $\mathbf{1} \cdot \mathrm{MeOH}$, additional X-ray diffraction experiments were performed at several temperatures between 100 and $385 \mathrm{~K}$. The X-ray study showed single crystal to single crystal phase transition with solvent loss at annealing the crystal at $350 \mathrm{~K}$ in nitrogen stream. According to crystal structure refinement, the methanol site is fully occupied at $295 \mathrm{~K}$ [refining the occupancy gives value of 0.988(4)]. Process of solvent removal has started at the end of the 24-h X-ray experiment at $340 \mathrm{~K}$ [refined MeOH occupancy value is 0.956(6)]. It has been empirically found that annealing of the crystal at $350 \mathrm{~K}$ during one day transforms the crystal completely into a new phase with chemical formula [Fe(III)( $\mathrm{sal}_{2}$-trien)](TCNQ) $)_{2}(\mathbf{1})$, i.e., totally free of solvent. All further diffraction experiments were done for the new phase 1, overall sequence of temperature changes being following: warming to 350 and $385 \mathrm{~K}$, further cooling to 295 and $220 \mathrm{~K}$ and again warming to 260 and $325 \mathrm{~K}$ with full data collection at all these temperatures. The treatment to carry out X-ray study at $400 \mathrm{~K}$ was unsuccessful due to melting of the crystal. Thus, temperatures of solvent loss and crystal decay in the X-ray experiments appeared to be about $50-80 \mathrm{~K}$ lower than the temperatures of corresponding peaks in DSC spectrum that is associated with the distinctly different conditions of heating in X-ray and thermogravimetric experiments. 
Symmetry of the crystal (triclinic $P \overline{1}$ ) persists upon the transition, but solvent loss causes significant distortion of the lattice (Materials and Methods). Relatively large temperature-dependent structural changes have been found in both cationic magnetic and anionic conducting layers. They are accumulated in Table 1 and Figure 4. All the structural parameters investigated show discontinuous changes between 340 and $350 \mathrm{~K}$ at the transition from solvate to solvent-free phase. In the magnetic subsystem, the Fe-N bond lengths and dihedral angle $\alpha$ between two phenoxy groups in the $\left[\mathrm{Fe}(\mathrm{III})\left(\mathrm{sal}_{2} \text {-trien) }\right]^{+}\right.$cation, both of which are sensitive to spin state of the complex, show linear temperature dependences in the $100-340 \mathrm{~K}$ range and notably increase at $350 \mathrm{~K}$ (Figure 4a). An abrupt growth of these parameters reflects transition of Fe(III) from LS $(S=1 / 2)$ to HS state $(S=5 / 2)$. The mean $\mathrm{Fe}-\mathrm{N}_{\text {imine }}$ and $\mathrm{Fe}-\mathrm{N}_{\text {amine }}$ bond length values increase from 1.94 and $2.01 \AA$, typical for the LS $\mathrm{Fe}(\mathrm{III})$, to 2.00 and $2.08 \AA$, respectively, at $385 \mathrm{~K}$. Taking into account corresponding average $\mathrm{Fe}-\mathrm{N}$ distances in high-spin state, 2.12 and $2.20 \AA$ [26,34], one can presume that about one third of iron centers are $\mathrm{HS}$ at this temperature. Stronger distortion of the $\mathrm{FeN}_{4} \mathrm{O}_{2}$ octahedron at $385 \mathrm{~K}$ (diagonal angles are $164^{\circ}-177^{\circ}$, Table S2) is an additional evidence of partial transition to HS state. It should be emphasized that in the temperature range $100-340 \mathrm{~K}$, in which the solvate phase $1 \cdot \mathrm{MeOH}$ exists, the $\mathrm{Fe}-\mathrm{N}$ bonds correspond to LS state and do not show any notable growth. In the solvent-free phase $\mathbf{1}$ a reversible character of SCO transition is observed at further temperature cycling. The Fe-N bond lengths return to initial, typical for LS Fe(III) values on cooling to $220 \mathrm{~K}$ and go again to HS values on a new cycle of warming (empty marks in Figure 4a) but in the phase $\mathbf{1}$ these changes are smooth, without jump. The angle $\alpha$ in $\mathbf{1}$ at low temperatures is larger than it was in $\mathbf{1} \cdot \mathrm{MeOH}$ (Figure $4 \mathrm{a}$ ) reflecting appearance of an additional space in the crystal lattice of the solvent-free phase.

Table 1. The average $\mathrm{Fe}-\mathrm{N}_{\text {imine }}$ and $\mathrm{Fe}-\mathrm{N}_{\text {amine }}$ bond length values and dihedral angle $\alpha$ between two phenoxy groups in $\left[\mathrm{Fe}(\mathrm{III})\left(\mathrm{sal}_{2} \text {-trien) }\right]^{+}\right.$cation in $\mathbf{1} \cdot \mathrm{MeOH}$ and $\mathbf{1}$, the charges $(\delta)$ of different $\mathrm{TCNQ}^{\bullet-}$ species I and II estimated from Kistenmacher's empirical formula (Table S1) [41] and then scaled to make the total charge on TCNQ pair exactly equal to -1 and intrastack I-I, I-II and II-II interplanar separations at different temperatures.

\begin{tabular}{|c|c|c|c|c|c|c|c|c|c|c|}
\hline Parameter & $\begin{array}{c}1 \cdot \mathrm{MeOH} \\
100 \mathrm{~K}\end{array}$ & $\begin{array}{c}1 \cdot \mathrm{MeOH} \\
220 \mathrm{~K}\end{array}$ & $\begin{array}{c}\text { 1·MeOH } \\
295 \mathrm{~K}\end{array}$ & $\begin{array}{c}1 \cdot \mathrm{MeOH} \\
340 \mathrm{~K}\end{array}$ & $\begin{array}{c}1 \\
350 \mathrm{~K}\end{array}$ & $\begin{array}{c}1 \\
385 \mathrm{~K}\end{array}$ & $\begin{array}{c}1 \\
325 \mathrm{~K}\end{array}$ & $\begin{array}{c}1 \\
295 K\end{array}$ & $\begin{array}{c}1 \\
260 \mathrm{~K}\end{array}$ & $\begin{array}{c}1 \\
220 \mathrm{~K}\end{array}$ \\
\hline av. $\left(\mathrm{Fe}-\mathrm{N}_{\mathrm{im}}\right), \AA$ & $1.936(8)$ & $1.935(7)$ & $1.936(8)$ & $1.942(9)$ & $1.97(2)$ & $2.00(2)$ & $1.96(2)$ & $1.945(15)$ & $1.931(13)$ & $1.934(9)$ \\
\hline av. $\left(\mathrm{Fe}-\mathrm{N}_{\mathrm{am}}\right), \AA$ & $2.007(2)$ & $2.006(4)$ & $2.010(4)$ & $2.014(2)$ & $2.05(2)$ & $2.08(2)$ & $2.035(17)$ & $2.021(10)$ & $2.005(8)$ & $2.009(6)$ \\
\hline$\alpha^{\circ}$ & $53.87(6)$ & $55.57(5)$ & $56.71(4)$ & $57.65(8)$ & $64.00(11)$ & $66.12(12)$ & $62.93(9)$ & $62.01(7)$ & $61.39(6)$ & $60.81(5)$ \\
\hline$\delta(\mathbf{I})$ & -0.39 & -0.46 & -0.47 & -0.44 & -0.49 & -0.51 & -0.47 & -0.44 & -0.44 & -0.39 \\
\hline$\delta(\mathrm{II})$ & -0.61 & -0.54 & -0.53 & -0.56 & -0.51 & -0.49 & -0.53 & -0.56 & -0.56 & -0.61 \\
\hline I-I, $\AA$ & $3.274(4)$ & $3.254(5)$ & $3.272(8)$ & $3.293(9)$ & $3.313(5)$ & $3.322(6)$ & $3.317(7)$ & $3.316(7)$ & $3.301(7)$ & $3.310(9)$ \\
\hline I-II, Å & $3.19(4)$ & $3.27(4)$ & $3.31(4)$ & $3.33(4)$ & $3.31(4)$ & $3.34(4)$ & $3.31(5)$ & $3.29(5)$ & $3.26(5)$ & $3.24(5)$ \\
\hline II-II, Å & $3.297(6)$ & $3.344(6)$ & $3.377(6)$ & $3.404(5)$ & $3.457(8)$ & $3.480(7)$ & $3.450(8)$ & $3.432(10)$ & $3.394(9)$ & $3.371(9)$ \\
\hline
\end{tabular}

In contrast to the magnetic subsystem, changes in the conducting TCNQ layer occur in the entire temperature range investigated. Two independent $\mathrm{TCNQ}^{\bullet \delta}-$ radical anions show tendency to a leveling of their charge state on warming (Figure $4 \mathrm{~b}$ ). Charges on TCNQ ${ }^{\bullet-}-$ I and II radicals were calculated at different temperatures using the Kistenmacher formula (Table S1) and then scaled to make the total charge on the TCNQ pair exactly equal to -1 according to stoichiometry of the compound. The resulted scaled values are used in Table 1 and Figure $4 \mathrm{~b}$. Difference in charge on TCNQ ${ }^{\bullet-}$ I and II observed at $100 \mathrm{~K}$ fully disappears at $385 \mathrm{~K}$ and both of the anions become half-charged. Evolution of the charge is not uniform in 100-340 K range showing minimum for I and maximum for II at about room temperature. There is a jump at $350 \mathrm{~K}$ equalizing the charges. Further cooling leads to a linear divergence of charges to the starting values. Temperature evolution of the interplane separations along the TCNQ stack is not similar for three types of interactions: I-II and II-II distances grow on warming whereas I-I has a minimum at $220 \mathrm{~K}$ (Figure 4c). Again there are clear jumps on the heating curves in Figure $4 \mathrm{c}$ in the 340-350 K region and near linear reverse way on cooling. In absolute scale growth of II-II separation between the TCNQ tetrads is maximal in comparison with I-I and I-II inside the 
tetrad. No C. . . C contact shorter than $3.4 \AA$ is observed in the II. . . II interaction at 385 K. It is believed that the tetrads in HS phase are more isolated from one another along the stacks. Overlap modes in the stack change insignificantly.
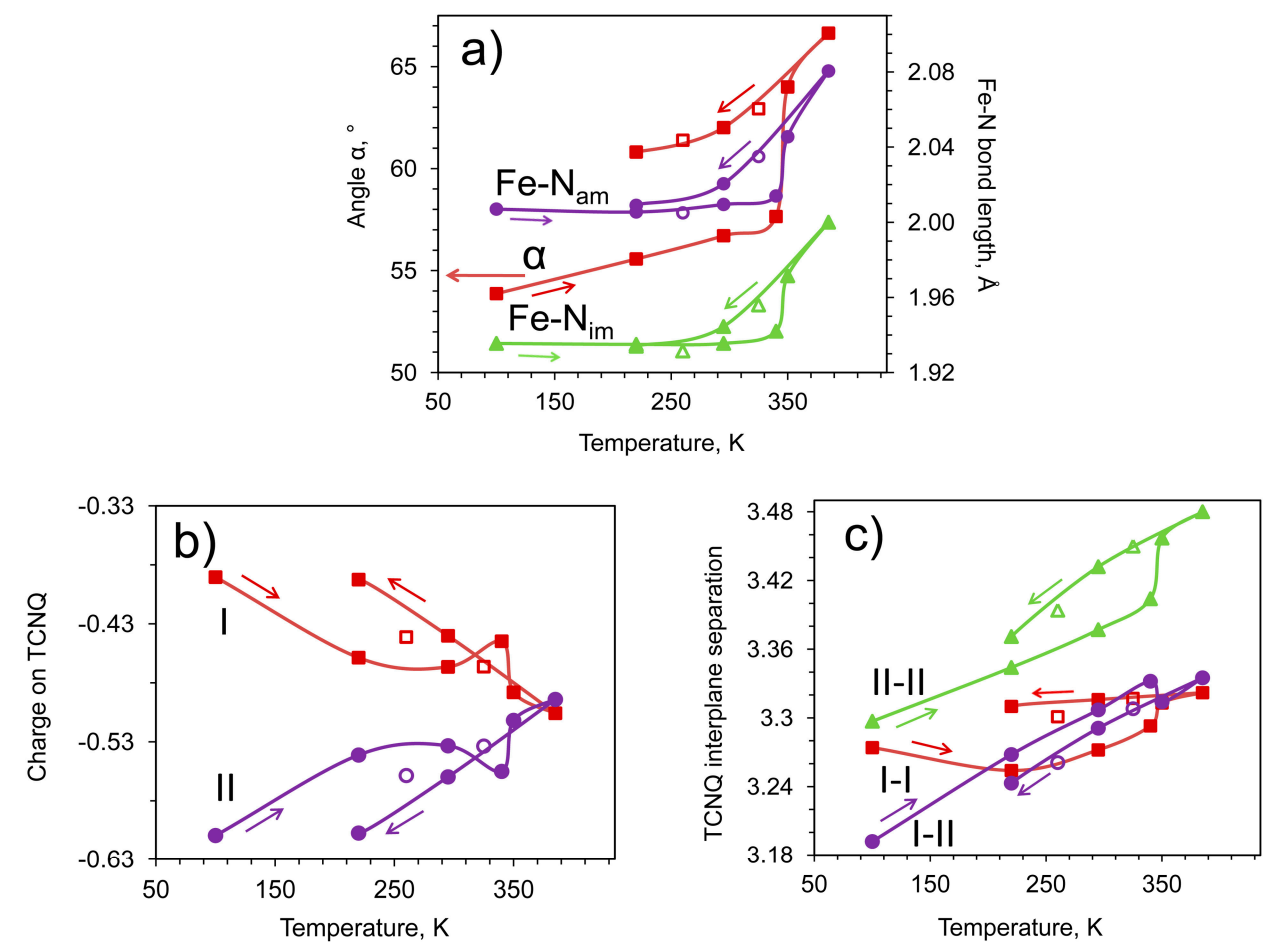

Figure 4. Temperature dependences of mean $\mathrm{Fe}-\mathrm{N}_{\mathrm{amine}}$ and $\mathrm{Fe}-\mathrm{N}_{\text {imine }}$ bond length values and dihedral angle $\alpha$ between two phenoxy arms in the cation (a); TCNQ ${ }^{\bullet-} \mathbf{I}$ and II charges (b) and interplane separations I-I, I-II and II-II in TCNQ stack (c). Starting point was at $100 \mathrm{~K}$, warming from 100 to $385 \mathrm{~K}$ was followed by cooling from 385 to $220 \mathrm{~K}$ (see arrows) and new warming from 220 to $325 \mathrm{~K}$ (points corresponding to second warming are shown by empty marks). The data points obtained while warming in the range $100 \mathrm{~K}$ to $340 \mathrm{~K}$ belong to the solvate phase $1 \cdot \mathrm{MeOH}$. The parameters obtained while warming above $350 \mathrm{~K}$ and further cooling correspond to the solvent-free phase 1.

\subsection{2. $\left[\mathrm{Fe}(\mathrm{III})\left(\mathrm{sal}_{2}\right.\right.$-trien) $](\mathrm{TCNQ}) \cdot \mathrm{CH}_{3} \mathrm{CN}(2)$}

The asymmetric unit of the triclinic $P \overline{1}$ unit cell at $100 \mathrm{~K}$ includes one $\mathrm{TCNQ}^{-}$anion, one $\left[\mathrm{Fe}\left(\mathrm{sal}_{2} \text {-trien) }\right]^{+}\right.$cation and one acetonitrile molecule in general positions (Figure 5).

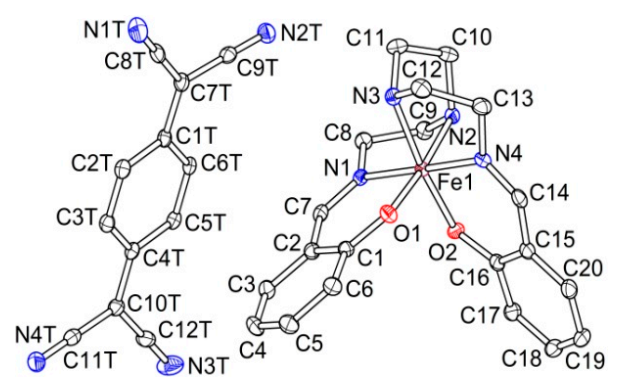

Figure 5. Asymmetric unit in 2 (ORTEP drawing with $50 \%$ probability ellipsoids, solvent molecule is omitted).

The crystal structure is built of the dianionic $\left(\mathrm{TCNQ}_{2}\right)^{2-}$ dimers surrounded by $\left[\mathrm{Fe}\left(\mathrm{sal}_{2} \text {-trien) }\right]^{+}\right.$ cations (Figure S5). According to the 1:1 stoichiometry of the complex, the TCNQ charge is -1 that 
agrees with charge calculations on the base of bond lengths values (Table S1). The adjacent dimers interact along $a$ by hydrogen $\mathrm{C}-\mathrm{H} . . \mathrm{N} \equiv \mathrm{C}$ contacts (H. . . N distances of $2.59,2.62 \AA$ ). The $\mathrm{Fe}(\mathrm{III})$ cation in $\left[\mathrm{Fe}\left(\mathrm{sal}_{2} \text {-trien) }\right]^{+}\right.$is octahedrally surrounded by four $\mathrm{N}$ and two $\mathrm{O}$ atoms of the ligand. Short $\mathrm{Fe}-\mathrm{N}_{\text {imine }}, \mathrm{Fe}-\mathrm{N}_{\text {amine }}$ and $\mathrm{Fe}-\mathrm{O}$ bonds in the octahedron [average values are 1.931(3), 2.006(1) and 1.880(1) $\AA$, respectively, Table S3], minor distortion of the octahedron (the diagonal N-Fe-N, N-Fe-O angles are close to linear, Table S3) and small dihedral angle between the two phenoxy mean planes (Figure $3 \mathrm{~b}$ ) are sings of the LS state of $\mathrm{Fe}(\mathrm{III})$ at $100 \mathrm{~K}$. The nearest cations are coupled by $\pi \ldots \pi$ stacking of the aromatic rings with seven C...C contacts in the range 3.369(3)-3.583(4) A (Figure S6). There is a hydrogen bonding between cation and anion $(\mathrm{N}-\mathrm{H} . . \mathrm{N}, \mathrm{H} \ldots \mathrm{N}=2.17 \AA ; 7 \mathrm{C}-\mathrm{H} . . \mathrm{N}$ with $\mathrm{H} . . \mathrm{N}=2.53-2.74 \AA$, Figure S6) as well as between cation and solvent $(\mathrm{N}-\mathrm{H} \ldots \mathrm{N}, \mathrm{H} . \mathrm{N}=2.18 \AA$; $\mathrm{C}-\mathrm{H} . . \mathrm{N}, \mathrm{H} . . \mathrm{N}=2.67 \AA$ ).

In order to investigate temperature behavior of the structure, additional X-ray diffraction experiments were carried out on the crystal 2 at 220, 295 and $325 \mathrm{~K}$. There was no indication of spin transition in the 100-325 K range because the mean $\mathrm{Fe}-\mathrm{N}_{\text {imine }}$ and $\mathrm{Fe}-\mathrm{N}_{\text {amine }}$ bond length values as well as dihedral angle $\alpha$ between two phenoxy groups in the $\left[\mathrm{Fe}(\mathrm{III})\left(\mathrm{sal}_{2} \text {-trien) }\right]^{+}\right.$cation remain almost unchanged (Table 2). At $350 \mathrm{~K}$ the diffraction quality sharply decreases, apparently, due to solvent loss. Disappearance of the long range order in the crystal makes impossible further structural investigation of the spin-crossover transition.

Table 2. The average $\mathrm{Fe}-\mathrm{N}_{\text {imine }}$ and $\mathrm{Fe}-\mathrm{N}_{\text {amine }}$ bond length values and dihedral angle $\alpha$ between two phenoxy groups in $\left[\mathrm{Fe}(\mathrm{III})\left(\mathrm{sal}_{2} \text {-trien) }\right]^{+}\right.$cation in $\mathbf{2}$ and interplanar separations $d$ in the TCNQ dimer at different temperatures.

\begin{tabular}{ccccc}
\hline Parameter & $\mathbf{2}$ & $\mathbf{2}$ & $\mathbf{2}$ & $\mathbf{2}$ \\
& $\mathbf{1 0 0} \mathbf{~ K}$ & $\mathbf{2 2 0} \mathbf{K}$ & $\mathbf{2 9 5} \mathbf{~ K}$ & $\mathbf{3 2 5} \mathbf{~}$ \\
\hline av. $\left(\mathrm{Fe}-\mathrm{N}_{\mathrm{im}}\right), \AA$ & $1.931(3)$ & $1.927(1)$ & $1.927(2)$ & $1.931(7)$ \\
av. $\left(\mathrm{Fe}-\mathrm{N}_{\mathrm{am}}\right), \AA$ & $2.006(1)$ & $2.003(2)$ & $2.007(2)$ & $2.013(3)$ \\
$\alpha, \stackrel{\circ}{ }$ & $77.23(4)$ & $77.85(5)$ & $78.02(5)$ & $77.96(6)$ \\
$d, \AA$ & $3.044(4)$ & $3.071(9)$ & $3.097(12)$ & $3.112(13)$ \\
\hline
\end{tabular}

\subsection{Conductivity and Magnetic Properties}

The normalized dc resistance, $R(T) / R(300 \mathrm{~K})$, was measured by a standard four-probe method for the single crystal $\left[\mathrm{Fe}(\mathrm{III})\left(\mathrm{sal}_{2}\right.\right.$-trien $\left.)\right](\mathrm{TCNQ})_{2} \cdot \mathrm{CH}_{3} \mathrm{OH}(\mathbf{1} \cdot \mathrm{MeOH})$ along the TCNQ stacks. It demonstrated a semiconducting type behavior (Figure 6). The placement of the electrodes on the crystal is shown in Figure S1. The value of the conductivity at room temperature is $1.5 \Omega^{-1} \cdot \mathrm{cm}^{-1}$. Below $110 \mathrm{~K}$ the data points were well described by the exponential law $R_{\text {theor }}(T)=\exp (\Delta E / \mathrm{k} T)$ with the energy gap $\Delta E=0.05 \mathrm{eV}$ (inset, Figure 6).

The results of the Montgomery method measurements (see Materials and Methods) at $300 \mathrm{~K}$ for the in-plane $\left(\sigma_{\mid} \mid\right.$TCNQstacks $)$and out-of-plane $\left(\sigma_{\perp}\right)$ conductivity tensor components accounted for $5.4 \Omega^{-1} \cdot \mathrm{cm}^{-1}$ and $3 \times 10^{-3} \cdot \Omega^{-1} \cdot \mathrm{cm}^{-1}$, respectively. Thus, the conductivity anisotropy $\left(\sigma_{|| \mathrm{TCNQstacks}} / \sigma_{\perp}\right)$ was equal to $1.8 \times 10^{3}$, while the anisotropy in the plane was noticeably less $\left(\sigma_{\mid} \mid \mathrm{TCNQ}\right.$ stacks $/ \sigma_{\perp \mathrm{TCNQ}}$ stacks $\left.=30\right)$.

The conductivity at room temperature for crystals $1 \cdot \mathrm{MeOH}$ was $1-2$ order of magnitude higher, and the activation energy was an order less, than those reported for conducting SCO complexes of $\mathrm{Fe}(\mathrm{II})$ and $\mathrm{Co}(\mathrm{II})$ with TCNQ in a fractional reduction state $[32,33,40]$. This difference was associated with the structure of the TCNQ stacks. In $\mathbf{1} \cdot \mathrm{MeOH}$, the stacks are rather regular by charge distribution and intermolecular separation, while in the other structures the stacks are subdivided into the pronounced TCNQ triads. It should be noted, that the complex $1 \cdot \mathrm{MeOH}$ along with $\left[\mathrm{Fe}(\mathrm{III})(\mathrm{qsal})_{2}\right]\left[\mathrm{Ni}(\mathrm{dmit})_{2}\right]_{3} \cdot \mathrm{CH}_{3} \mathrm{CN} \cdot \mathrm{H}_{2} \mathrm{O}\left(\sigma=2.0 \Omega^{-1} \cdot \mathrm{cm}^{-1}\right)$ [29] possesses a record conductivity among known conducting SCO complexes. In contrast to $1 \cdot \mathrm{MeOH}$, complex 2 was practically an insulator $\left(\sigma_{300 \mathrm{~K}}=10^{-8} \Omega^{-1} \cdot \mathrm{cm}^{-1}\right)$, that is characteristic of many TCNQ salts with a fully reduced 
TCNQ. The low conductivity is associated primarily with a strong dimerization of TCNQ radicals and absence of a long-range stacking.

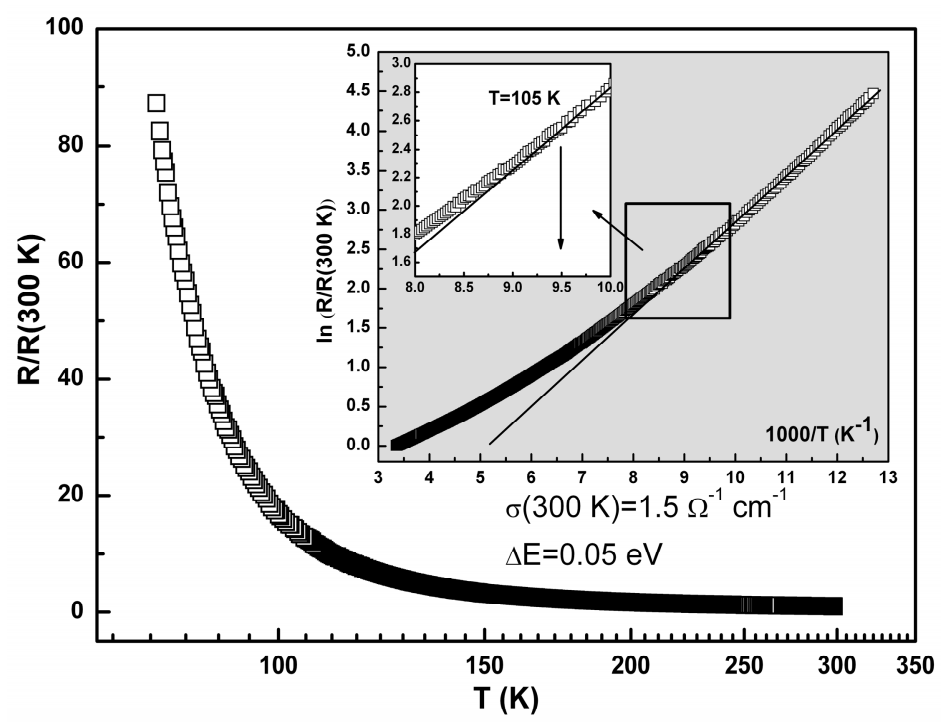

Figure 6. Temperature dependence of the normalized resistance, $R(T) / R(300 \mathrm{~K})$ for $\mathbf{1} \cdot \mathrm{MeOH}$, in the logarithmic scale. Inset-the plot of $R(T) / R(300 \mathrm{~K})$ vs. scaled reciprocal temperature, 1000/T. Solid line is the best fit curve in the range $78 \mathrm{~K}<T<110 \mathrm{~K}, R_{\text {theor }}(T)=\exp (\Delta E / \mathrm{k} T)$, with the energy gap $\Delta E=0.05 \mathrm{eV}$. Zoomed window-a deviation of the experimental data from the theoretical curve starting above $105 \mathrm{~K}$.

The bulk static magnetic susceptibility $\chi$ of $\mathbf{1} \cdot \mathrm{MeOH}$ was measured on a polycrystalline sample in the temperature range of $2-400 \mathrm{~K}$ (Figure $7 \mathrm{a}$ ). The entire range was scanned twice at rates $5 \mathrm{~K} / \mathrm{min}$ in the interval $20-400 \mathrm{~K}$ and $0.5 \mathrm{~K} / \mathrm{min}$ at the interval $2-20 \mathrm{~K}$. The exposure time at the highest temperature $400 \mathrm{~K}$ was $10 \mathrm{~min}$. Two cycles of measurements at external field values $0.1 \mathrm{~T}$ and $4.0 \mathrm{~T}$ provided coinciding data points above $20 \mathrm{~K}$. The data of the latter cycle were omitted in Figure 7. The value of spin response below $100 \mathrm{~K}$ indicated that $\sim 98 \%$ of Fe(III) ions exist in LS state. Spin response of conducting TCNQ sublattice appeared to be negligible within less than $10 \%$ $\left(\chi \leq 2 \times 10^{-2} \mathrm{~cm}^{3} \cdot \mathrm{K} \cdot \mathrm{mol}^{-1}\right)[42,43]$. This is in agreement with earlier measured spin response of TCNQ layers in conducting Fe(II) SCO system [40]. A temperature independent contribution (TIP) to the spin susceptibility was also found insignificant for the description of the low temperature evolution of $\chi(T)$ in Figure 7a. A total magnetization, $M(B)$, measured at $2 \mathrm{~K}$ (Figure $7 \mathrm{~b}$ ), was described by a Brillouin curve for $\mathrm{S}=1 / 2$ (solid line). Thus, a paramagnetic response of $\mathbf{1} \cdot \mathrm{MeOH}$ below $100 \mathrm{~K}$ is related to the local moments $S=1 / 2$ of LS Fe(III).

Sharp growth of $\chi T$ above $\sim 150 \mathrm{~K}$ is consistent with the structural changes in TCNQ sublattices (Figure $4 \mathrm{~b}, \mathrm{c}$ ) and deviation of the resistivity from the exponential law (Figure 6). It arises due to SCO transition and can be modeled by replacing $S=1 / 2$ to $S=5 / 2$ magnetic moments via Boltzmann activation mechanism [40]. A respective curve is shown in Figure 7 (inset). The SCO parameters were $T^{*}=410 \mathrm{~K}$ and $\Delta T_{1 / 2}=108 \mathrm{~K}$ for the mid point and the width of the transition at the levels $\pm 1 / 2$ of the midpoint. In contrast to the diffraction data, the behavior of the magnetic susceptibility was found completely reversible. This can be understood in terms of different experimental conditions (measurement time window: minutes vs. hours, atmosphere: helium vs. nitrogen, etc.). A fully realized HS state was not achieved, because it rests above the stability threshold for this structure as it follows from the thermogravimetric analysis (Figure S2). We concluded that solvate methanol did not leave the structure while heating-cooling cycles in the magnetic measurements. A calculated value, $\chi T=4.4 \mathrm{~cm}^{3} \cdot \mathrm{K} \cdot \mathrm{mol}^{-1}$, seemed a reliable estimate for total the spin response in HS state even though a complete was not achieved experimentally (Figure 7a, inset). A continuous transition curve allows 
determining mutual concentrations of $S=1 / 2$ and $S=5 / 2$ moments at any temperature within the SCO range.
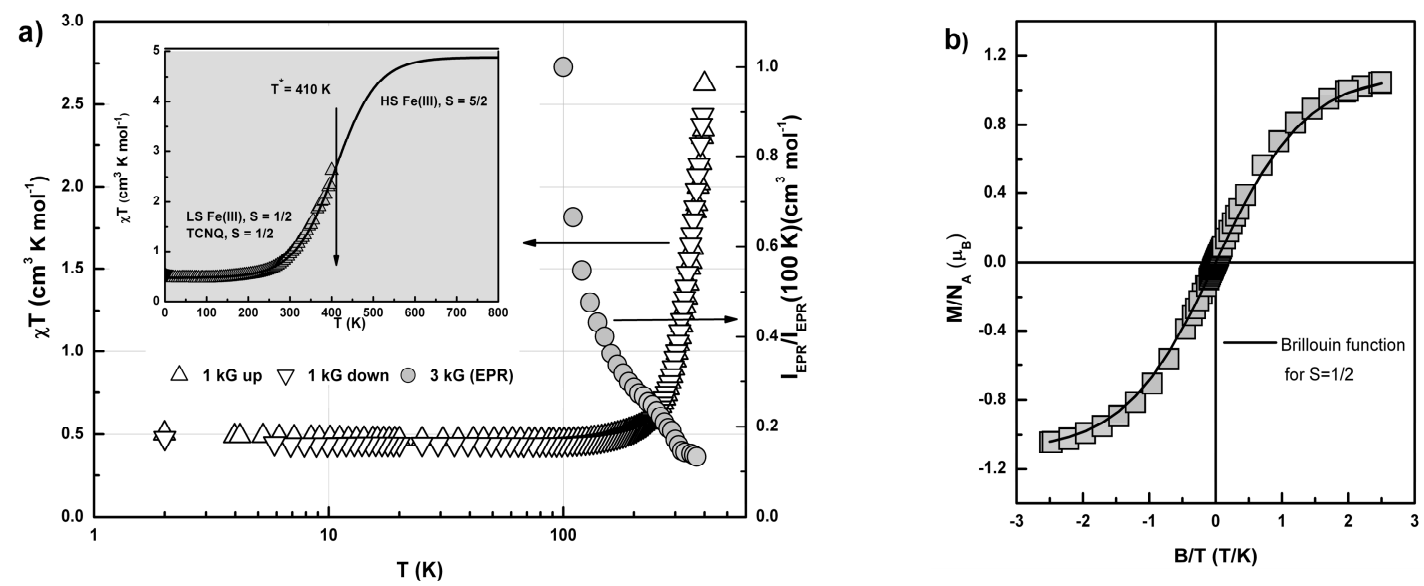

Figure 7. Temperature dependences (logarithmic scale) of the product $\chi T$ measured for $1 \cdot \mathrm{MeOH}$ by SQUID magnetometer $(\mathrm{B}=1 \mathrm{kG}$, heating $(\Delta)$ and cooling $(\nabla)$ regimes) and the relative spin concentration $I_{\mathrm{EPR}}(T) / I_{\mathrm{EPR}}(100 \mathrm{~K})$ measured by $\mathrm{EPR}(\mathrm{B}=3 \mathrm{kG}$, heating $(\bullet)$ regime) (a). Inset-detailed evolution of the $\chi T$ in the range of spin crossover transition between LS Fe(III) $S=1 / 2$ and HS Fe(III) $S=5 / 2$. Solid line is a simulation by a Boltzmann distribution. Field dependence of the magnetization, $M(B)$, measured at $T=2.0 \mathrm{~K}(\mathbf{b})$. Solid line denotes the Brillouin function for $\mathrm{S}=1 / 2$.

The EPR spectrum of $\mathbf{1} \cdot \mathrm{MeOH}$ at $100 \mathrm{~K}$ was an intensive signal with anisotropic $g$-factor: $g_{1}=2.219(9), g_{2}=2.171(0), g_{3}=1.961(5)$. The evolution of the lineshape while heating up to $370 \mathrm{~K}$ is shown in Figure $8 \mathrm{a}$. Temperature dependence of the $g$-components is presented in Figure $8 \mathrm{~b}$. The total spectrum was simulated at the temperatures of the measurement by using a standard lineshape model with anisotropic $g$-factor (WINEPR). The $g$-parameters were taken from the respective trend lines in Figure 8. An individual single line corresponding to the central $g$ component has been extracted and further analyzed in terms of a relaxation rate. Qualitatively the linewidth behavior, $\Delta B(T)$, can be traced in Figure 8 . Here we are showing the peak positions $B_{\mathrm{p}+}$ and $B_{\mathrm{p}-}$ for low- and high-field halves of the first derivative signal $\left(\Delta B=B_{\mathrm{p}^{-}}-B_{\mathrm{p}^{+}}\right)$. Therefore, we were able to avoid a $g$-strain effect and only analyze relaxation.

a)

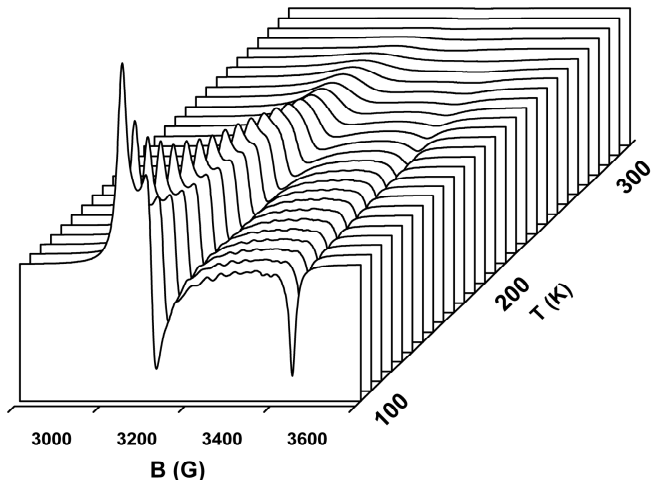

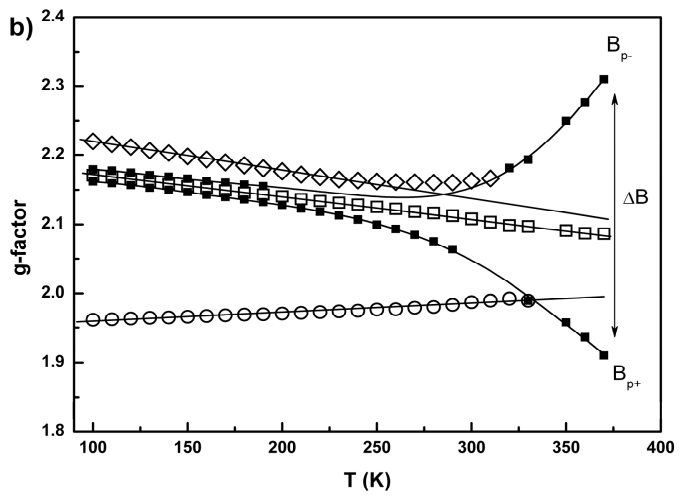

Figure 8. Temperature evolution of the EPR spectrum of $1 \cdot \mathrm{MeOH}$ in the range $100 \mathrm{~K}$ to $370 \mathrm{~K}$ (a). Temperature dependence of the $g$-values $\left(g_{1}(\diamond), g_{2}(\square), g_{3}(\bigcirc)\right)$ measured while heating in the range of SCO in 1.MeOH: (b). Solid straight lines are linear fits. Solid bold lines connecting squares $(\mathbf{\square})$ designate positions of the peaks $B_{\mathrm{p}+}$ and $B_{\mathrm{p}-}$ for a simulated central line of the spectrum corresponding to $g_{2}$. The peak-to-peak linewidth of the central line is $\Delta B=B_{\mathrm{p}^{+}}-B_{\mathrm{p}^{-}}$. 
The observed signal is a typical X-band spectrum of LS Fe(III) with $S=1 / 2$ in six-coordinated position. When a geometry of the ligand changes (for example a dihedral angle $\alpha$ in Figure 4a), the symmetry of hexa-coordination would also change, from rhombic distortions to axial symmetry. Axial symmetry arises in HS state due to Jahn-Teller effect. In various $4 \mathrm{~N}$-coordinated chelate sites the $g_{1}$ value reaches 3.0 following the ascending linear trend when coordination geometry gradually changes to axial symmetry [44]. In other words, $g_{1}$ is a sensitive probe of ligand geometry as well as a solvent presence. On contrary to expected, $g_{1}$ and $g_{2}$ components in our experiment demonstrated weakly descending trend with the temperature. This is in an indicative agreement with unchanged $\mathrm{F}-\mathrm{N}_{\mathrm{am}}$ and $\mathrm{Fe}-\mathrm{N}_{\mathrm{im}}$ distances in Figure 4a. This also implies that the coordination geometry in LS complexes [Fe(III)(sal ${ }_{2}$-trien)] remains sustainable up to $370 \mathrm{~K}(63 \% \mathrm{LS}, 37 \% \mathrm{HS})$. Variation of the dihedral angle between two phenoxy arms within $\sim 5^{\circ}$ does not cause a systematic effect on electronic structure of the metal cation. The HS configuration arises due to spontaneous thermal activation, without a precursor. The X-band spectrum for HS Fe(III), $S=5 / 2$, usually shows a strong line at $g=6$ ( $900 \mathrm{G}<B<1400 \mathrm{G}$ ) and a complimentary weak absorption at $g \approx 2.0$ [45-47]. This is because the $\mathrm{S}=5 / 2$ multiplet $\left({ }^{6} \mathrm{~A}_{1}\right)$ forms three Kramers' doublets that are separated by energies significantly larger than the microwave quantum, $\sim 0.3 \mathrm{~cm}^{-1}$ for X-band. For higher rhombicities (E/D) an additional line arises at $g=4.3$ due to quantum-mechanically mixed states. We detected none of the three lines in the range $100-370 \mathrm{~K}$. Since the contribution of $\mathrm{HS} \mathrm{Fe}(\mathrm{III})$ magnetic moments in $\mathbf{1} \cdot \mathrm{MeOH}$ was determined by SQUID measurements, this is an indication of fast spin relaxation. As we show further, this signal was observed in the insulating compounds 2 and 3 . Hence, fast relaxation of $S=5 / 2$ moments is caused by spin-spin interactions with mobile spins in TCNQ sublattice.

The concentration of LS [Fe(III)( sal $_{2}$-trien)] complexes was independently verified by EPR. According to Schumacher-Slichter method a double integrated intensity of the total EPR spectrum, $I_{\mathrm{EPR}}$, is proportional to the respective spin concentration [48]. This method works best for spin $\mathrm{S}=1 / 2$ and detection of relative changes. The absolute values determined at high temperatures and/or for broad spectra are less reliable. The product $I_{\mathrm{EPR}} T$, corresponding to the intensity $I_{\mathrm{EPR}}(T) / I_{\mathrm{EPR}}(100 \mathrm{~K})$ in Figure 7, has decreased 1.48 times by $370 \mathrm{~K}$ giving the estimate $67 \%$. This is in good agreement with $63 \%$ portion of $S=1 / 2$ moments obtained from SQUID data at the same temperature.

Local magnetic moments of LS Fe(III) can be considered as a useful probe for studying spin-spin interactions in the process of spin crossover. Indeed, the local environment remains stable as it follows from the behavior of $g$-tensor, whereas the linewidth experiences an abrupt broadening. The value of partial linewidth, $\Delta B$, at $100 \mathrm{~K}$ was $18.8 \mathrm{G}$, that corresponds to a spin-lattice relaxation in an individual isolated complex LS [Fe(III)(sal ${ }_{2}$-trien)] at finite temperature. Figure 9 demonstrates a sharp growth of $\Delta B$ at increasing relative concentration of the moments $\mathrm{S}=5 / 2, n / \mathrm{N}(\%)$. The value of $n / \mathrm{N}$ was extracted from the magnetic susceptibility data in Figure 7a (inset). This growth was fitted well by a simple expression $\Delta B=\Delta \mathrm{B}_{0}+\mathrm{k}(n / \mathrm{N})$, where $\Delta \mathrm{B}_{0}=-46 \mathrm{G}$ is a base parameter relating to a threshold concentration $(4.8 \%)$ and $\mathrm{k}=21 \mathrm{G} / \%$ is a broadening factor. Weak and gradual broadening at the concentrations below $5 \%$ was reasonably affiliated with a trivial spin-phonon mechanism (spin-lattice relaxation). Above $5 \%$ the HS Fe(III) magnetic moments become a dominant source of relaxation. This is evidently a spin-spin relaxation. It looks credible that the relaxation rate in a reservoir $A(S=1 / 2)$ is proportional to the spin concentration in a reservoir $B(S=5 / 2)$. The question arises if this relaxation is of dipole-dipole nature, or a result of a weak superexchange coupling? The dipole-dipole could be a favorable mechanism once the dramatic broadening had been confirmed for other [Fe(III)( $\mathrm{sal}_{2}$-trien)] complexes. So far, we do not have the proofs. Exchange coupling might not seem a realistic scenario, unless the counterion system of TCNQ in a fractional reduction state, possessing highly mobile delocalized electrons. The abrupt broadening of the conduction electron EPR signal was observed in the SCO system $\left[\mathrm{Fe}(\mathrm{II})\left\{\mathrm{HC}(\mathrm{pz})_{3}\right\}_{2}\right](\mathrm{TCNQ})_{3}[40]$. Note, that $\mathrm{LS} \mathrm{Fe}(\mathrm{II})$ cation does not possess a magnetic moment. The broadening in the SCO range was related to the spin concentration of $\mathrm{HS} \mathrm{Fe(II)} \mathrm{ions} \mathrm{with}$ $\mathrm{S}=2$ [40]. Owing to the fractional reduction state TCNQ triads, tetrads or even dimers might serve as efficient mediator of spin-spin interactions, when a direct overlapping of $d$-orbitals does not exist. 
Absence of a direct exchange or superexchange does not eliminate a dynamic local spin density on ligands. In turn, ligand shell closely interacts with $\mathrm{CN}$ groups in TCNQ via a network of short contacts. This is a "bottleneck" junction, which facilitates cross relaxation and may affect the broadening factor $k$ [49]. One more argument that is favorable is the absence of EPR signal from TCNQ sublattice in 1. MeOH. A typical signal in TCNQ semiconductors has width in the range 1-10 G that makes it very detectable even at low concentrations. It was shown for the system $\left[\mathrm{Fe}(\mathrm{II})\left\{\mathrm{HC}(\mathrm{pz})_{3}\right\}_{2}\right](\mathrm{TCNQ})_{3}$ that at spin $S=2$ concentrations above $5 \%$ in the SCO subsystem this signal rapidly spreads [40]. If so, there is no question why we did not observe it in $\mathbf{1} \cdot \mathrm{MeOH}$ where $100 \%$ of $\mathrm{S}=1 / 2$ moments were presented at all temperatures below the SCO.

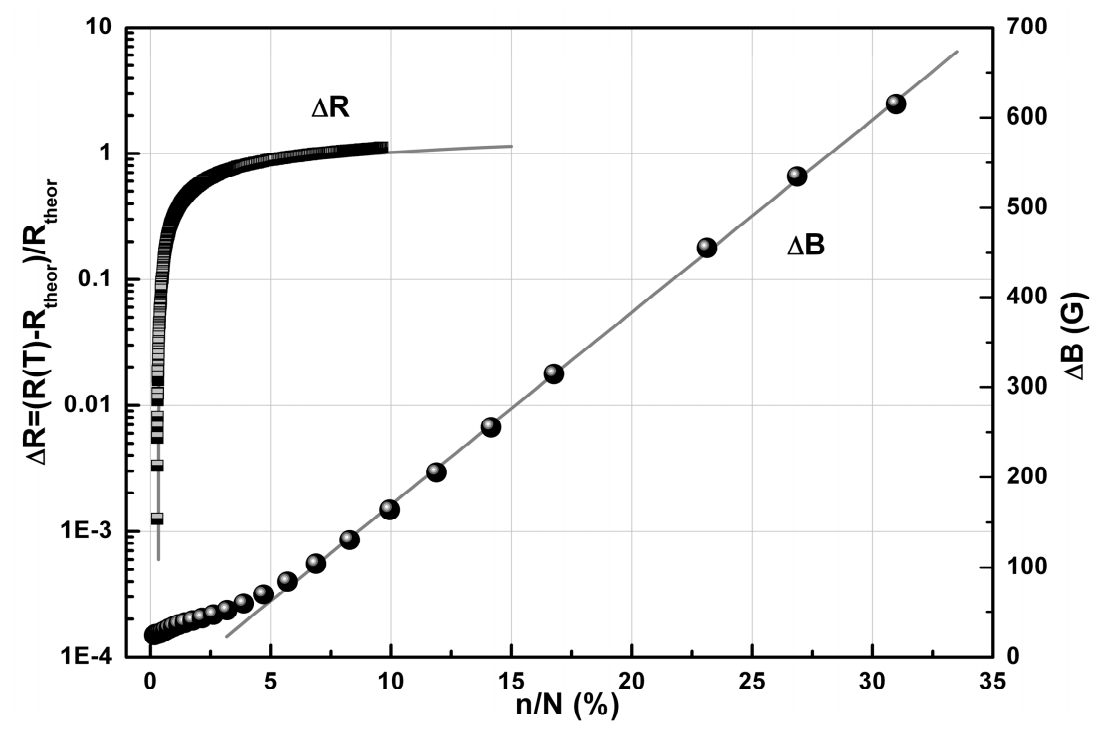

Figure 9. Partial EPR linewidth in 1.MeOH corresponding to the central $g_{2}$ component of $g$-factor $(\bullet)$, $\Delta B$, vs relative concentration of [Fe(III)(sal 2 -trien)] complexes in HS state, $n / \mathrm{N}(\%)$. Solid line is the best fit curve $\Delta B=\Delta \mathrm{B}_{0}+\mathrm{k}(n / \mathrm{N})$, where $\left|\Delta \mathrm{B}_{0}\right|=46 \mathrm{G}, \mathrm{k}=21 \mathrm{G} / \%$. Relative deviation of the resistance $(\mathbb{\square}), \Delta R=\left(R(T)-R_{\text {theor }}(T)\right) / R_{\text {theor }}(T)$, measured in the range $107 \mathrm{~K}<T<300 \mathrm{~K}$ vs. the concentration $n / \mathrm{N}(\%)$. Solid line is the best fit logarithmic curve $\Delta R(n / \mathrm{N})=\mathrm{A} \cdot \ln (3 n / \mathrm{N})$, where $\mathrm{A}=0.3$. The values $n / \mathrm{N}(\%)$ were extracted from the modeling transition curve in Figure $7 \mathrm{a}$ (inset).

As soon as delocalized spins in anion sublattice of $1 \cdot \mathrm{MeOH}$ were not detected by EPR, due to fast cross relaxation, and by SQUID, due to its negligible contribution to the total susceptibility, the only source of information about their reaction to SCO was an electron scattering. Below $110 \mathrm{~K}$ the resistance, $R(T) / R(300 \mathrm{~K})$, perfectly obeys thermal activation mechanism (Figure 6). One would expect that this mechanism also works at the higher temperatures, unless the structure of TCNQ stacks change substantially. Indeed, the gap of $\Delta=0.05 \mathrm{eV}$ corresponds to $600 \mathrm{~K}(\mathrm{kT})$, which is higher than $T^{*}=410 \mathrm{~K}$. Hence, theoretically the resistance was expected to follow the same trend in absence of SCO, $R_{\text {theor }}(T)$. However, the electron scattering can be affected by spin crossover due to local rearrangements inside the TCNQ tetrads I-II and II-II in the vicinity of HS complexes [Fe(III)( sal $_{2}$-trien)] (see Figure 4). For quantitative analysis we plotted a relative deviation of the actual resistance from its theoretical estimate, $\Delta R$, against the concentration of the HS complexes, $\Delta R=\left(R(n / \mathrm{N})-R_{\text {theor }}\right) / R_{\text {theor }}$, that was shown in Figure 9. The data were described by a logarithmic dependence $\Delta R=\mathrm{A} \cdot \ln (\mathrm{B} \cdot n / \mathrm{N})$, where $\mathrm{A}=0.3$ and $\mathrm{B}=3.0$. Note, that the argument $3 n / \mathrm{N}=n /(\mathrm{N} / 3)$ indicates that changes of resistivity occur in a reduced scale, $\sim(\mathrm{N} / 3)$. It is also worth to note, that the same type dependence was found for the in-plane components of the resistivity, $\rho_{||_{\mathrm{a}}}$ and $\rho_{\mid \mathrm{l}} \mathrm{b}$, in the conducting SCO complex $\left[\mathrm{Fe}\left\{\mathrm{HC}(\mathrm{pz})_{3}\right\}_{2}\right](\mathrm{TCNQ})_{3}[40]$. Moreover, it was shown in [40] that the transverse transport, $\rho_{\perp}(T)$, did not react to the changes in the cation layers. Therefore, we suggested that in $\mathbf{1} \cdot \mathrm{MeOH}$ all the observed changes of the resistance took place for the in-plane transport. Comparing data on Figure 9 
one can conclude, that the major effect of SCO on transport properties occurs at lower concentrations $n / \mathrm{N}<5 \%$, whereas spin-spin depolarization is effective at $n / \mathrm{N}>>5 \%$. Similar effect was observed in [40]. This is comprehensible and has a qualitative explanation. At the very low concentrations of HS $\left[\mathrm{Fe}(\mathrm{III})\left(\mathrm{sal}_{2}\right.\right.$-trien)] complexes, the local displacements inside and/or between the TCNQ tetrads behave as randomly distributed defects. As the temperature approaches the midpoint of the transition, the anion sublattice turns into a modulated structure or to a certain extent into an amorphous one, which depends on heating/cooling rates and cooperative effects. Hence, a scattering rate gets less sensitive. On contrary, the efficiency of a cross relaxation $1 / 2 \rightarrow 5 / 2$ depends on a capacity of the spin reservoir of $S=5 / 2$, i.e., concentration of the HS complexes within the interaction range. Thus, a momentum scattering and spin depolarization of conduction electrons in $\mathbf{1} \cdot \mathrm{MeOH}$ are decoupled to a large extent. In other words, this allows spin manipulation by an external source. It was found in [40], that for delocalized spin moments in the conducting layer depolarization is even more efficient, $\Delta B \sim(n / \mathrm{N})^{2}$. Once we obtain magnetically ordered local moments, we would get polarized conduction electrons.

The structures [Fe(III)( sal $_{2}$-trien)](TCNQ) $\cdot \mathrm{CH}_{3} \mathrm{CN}$ (2) and [Fe(III)( sal $_{2}$-trien)](TCNQ) $\mathrm{H}_{2} \mathrm{O}$ (3) could be viewed as the reference systems for distinguishing the effects of conduction electrons and solvent molecules in the magnetic and resonance properties of $\mathbf{1} \cdot \mathrm{MeOH}$. Solvent effects are responsible for the difference in their SCO transitions. The static magnetic susceptibility of $\mathbf{2}$ and $\mathbf{3}$ was measured in the range of $2-400 \mathrm{~K}$ four times, in two sequential cycles. Heating and cooling rates were taken the same as for $\mathbf{1} \cdot \mathrm{MeOH}$. The measurements begun at the room temperature in the external field $\mathrm{B}=4.0 \mathrm{~T}$. The virgin curves for the product $\chi T$ are shown in Figures 10 and $11((\square)$ data points) for 2 and 3, respectively. Upon cooling down to $2.0 \mathrm{~K}$ we measured the field dependences of the total magnetization by passing a complete field loop from $+4.0 \mathrm{~T} \rightarrow-5.0 \mathrm{~T} \rightarrow+5.0 \mathrm{~T} \rightarrow+0.1 \mathrm{~T}$. The exposure at liquid helium temperature lasted several hours. Then the magnetic susceptibility was measured second time at the field value $0.1 \mathrm{~T}(\Delta)$. The measurements at heating were finished at $360 \mathrm{~K}$, where the sample was exposed for about $10 \mathrm{~min}$. A second cycle started at $360 \mathrm{~K}$ by measurements at cooling down to $2.0 \mathrm{~K}(\nabla)$ and further heating up to $360 \mathrm{~K}(\bigcirc)$. Repeating field measurements were not performed. The $\chi T$ data for the heating curve of the cycle 2 in 3 are not shown in Figure 11, because we had to interrupt experiment due to technical reasons. We believe this was not critical for the discussion and conclusions.
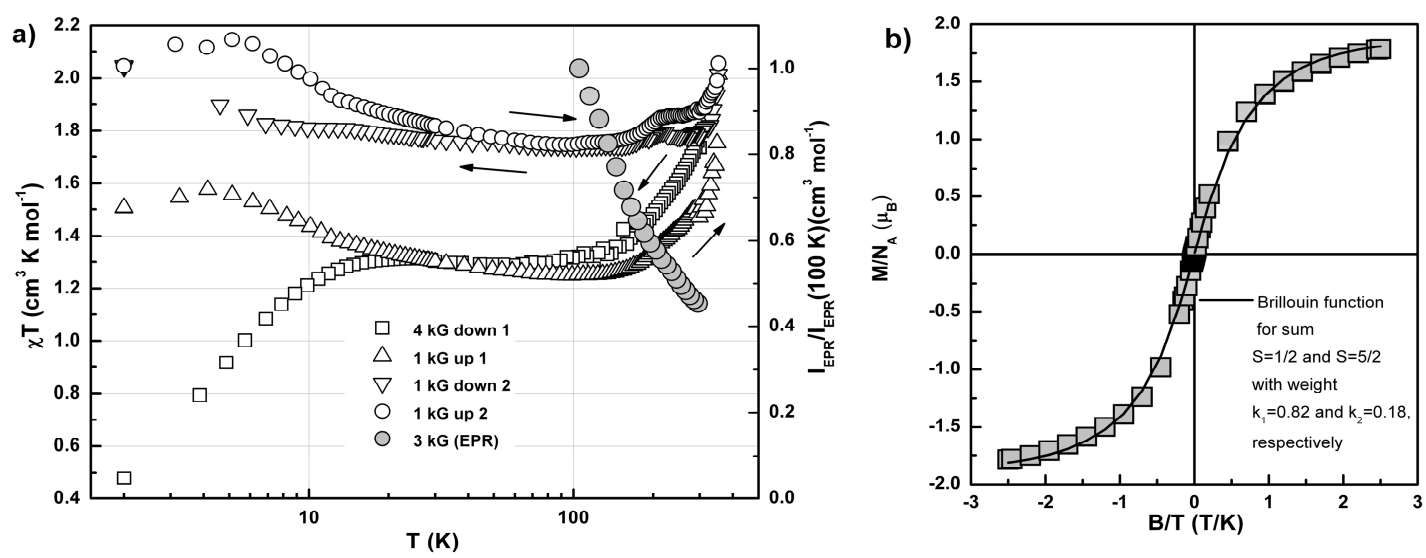

Figure 10. Temperature dependences (logarithmic OX scale) of the product $\chi T$ for 2 obtained in two heating-cooling cycles $(\mathrm{B}=1 \mathrm{kG}$, cycle 1: cooling $(\square)$, heating $(\Delta)$; cycle 2: cooling $(\nabla)$ and heating $(\bigcirc))$ and the relative spin concentration of $S=1 / 2, I_{\mathrm{EPR}}(\mathrm{T}) / I_{\mathrm{EPR}}(100 \mathrm{~K})$, measured by $\mathrm{EPR}(\mathrm{B}=3 \mathrm{kG}$, heating (•) regime) (a). Field dependence of the magnetization, $M(B)$, for 2 measured at $T=2.0 \mathrm{~K}(\mathbf{b})$. Solid line is the best fit curve corresponding to a weighted superposition of Brillouin functions for $S=1 / 2$ and $S=5 / 2$ (see main text for details). 

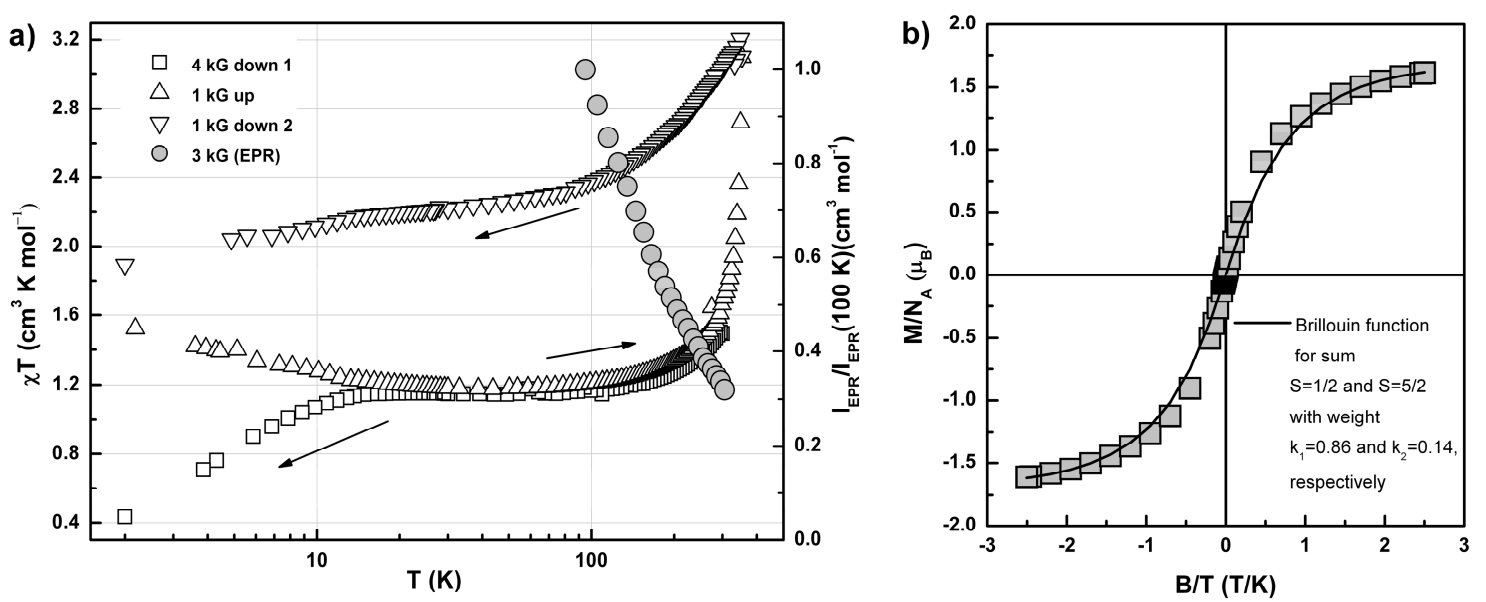

Figure 11. Temperature dependences (logarithmic OX scale) of the product $\chi T$ for $3(\mathrm{~B}=4.0 \mathrm{~T}$ : cooling $(\square)$ regime; $\mathrm{B}=0.1 \mathrm{~T}$ : heating $(\Delta)$ and cooling $(\nabla)$ regimes) and the relative spin concentration of $\mathrm{S}=1 / 2, I_{\mathrm{EPR}}(\mathrm{T}) / I_{\mathrm{EPR}}(100 \mathrm{~K})$, measured by EPR $(\mathrm{B}=3 \mathrm{kG}$, heating $(\bullet)$ regime) (a).Field dependences of the magnetization, $M(B)$, for 3 measured at $T=2.0 \mathrm{~K}$. Solid line is the best fit curve corresponding to a weighted superposition of Brillouin functions for $S=1 / 2$ and $S=5 / 2$ (see main text for details) (b).

It is worth to explain, how repeated measurements at the high and low fields, such as $4.0 \mathrm{~T}$ and $0.1 \mathrm{~T}$, allow accounting magnetic impurities. If a sample contains impurities (for example iron oxide nanoparticles from the solvent) with a contribution $\chi_{\mathrm{IMP}}$, it is practically difficult to subtract it from the total magnetic response in experiment, $\chi_{\exp }=\chi_{\mathrm{IMP}}+\chi_{\text {sample }}(T)$. In an ideal case, when $\chi_{\exp }$ coincides with the expected theoretical value, $\chi_{\text {sample }}{ }^{\text {theor }}$, the experimental data are entirely related to the spin system of the studied compound. This took place for $1 \cdot \mathrm{MeOH}$, so we did not present the high field data. In other cases, proofs would be required. The absolute values of $\chi_{\exp } T, 1.25$ and $1.75 \mathrm{~cm}^{3} \cdot \mathrm{K} \cdot \mathrm{mol}^{-1}$, measured respectively for $\mathbf{2}$ and $\mathbf{3}$ at $100 \mathrm{~K}$, were found considerably higher than their theoretical estimates for the LS state. The question is, whether this was a total spin response of SCO system, or it included the extrinsic component $\chi_{\text {IMP }}$. Magnetic response of the solid particles usually does not depend on the external field of a measurement, whereas the actual signal $\chi_{\text {sample }}$ is proportional to its strength. By performing measurement at a higher field, we reduced contribution of the extrinsic part, $\sim \chi_{\mathrm{IMP}} / \mathrm{B}$. Thus, a divergence of $\chi_{\exp } T$ data obtained at the various fields let us distinguish and account for external impurities, should they present in the sample. The negative side of the high field measurements is a descending trend, that arises due to insufficient population of upper spin state at higher Zeeman splitting (see the data points $(\square)$ below $15 \mathrm{~K}$ in Figures 10 and 11). Therefore, a temperature behavior below $20 \mathrm{~K}$ in Figures 10 and 12 was not discussed for the data points obtained at $4.0 \mathrm{~T}$. In the range near $100 \mathrm{~K}$ the values $\chi_{\exp } T$ measured at a broad span $0.1-4.0 \mathrm{G}$ pretty much coincide for both 2 and 3 . That means the absence of extrinsic magnetic contributions. We also asserted the absence of single radicals $\mathrm{TCNQ}^{\bullet-}$ as paramagnetic defects. Corresponding EPR signals [50] had negligible intensities, both in $\mathbf{2}$ and in $\mathbf{3}$ (Figure S8). These arguments as well as the measurement results allowed us to conclude, that the spin susceptibilities of 2 and 3 below $100 \mathrm{~K}$ were associated with the cation sublattice, namely with the magnetic moments of $\left[\mathrm{Fe}(\mathrm{III})\left(\mathrm{sal}_{2} \text {-trien) }\right]^{+}\right.$complexes.

The abrupt growth of $\chi T$ above $100 \mathrm{~K}$ confirms SCO transition for both systems, which is in agreement with that for $\mathbf{1} \cdot \mathrm{MeOH}$. Meanwhile, in both systems, 2 and 3, the transition showed a thermal hysteresis. Intricate hysteresis of spin susceptibility is typical for mononuclear iron (III) SCO complexes [51]. The absolute values of $\chi T$ contained a significant quantity of residual HS complexes at temperatures below $100 \mathrm{~K}$. The measurements in 2 yielded $80 \%$ of LS and $20 \%$ of HS complexes at $100 \mathrm{~K}$ in the cycle 1, and $69 \%$ of LS and 31\% of HS complexes in the cycle 2 (Figure 10). For 3 the $\chi T$ data were fitted with $76 \%$ of LS and $24 \%$ of HS complexes in the first cycle, and $68 \%$ to $32 \%$ in the second cycle, respectively (Figure 11). This is close to the balance ratio 2:1, which is evidently 
determined by a complete loss of solvent (2/3 complexes in LS state and 1/3-in HS state). Field dependences shown in Figures 10 and 11 also confirm, that considerable ferric entity remains in the HS state at $T=2 \mathrm{~K}$. Magnetization curves were successfully fitted with $82 \%$ and $18 \%$ for 2 (solid line in Figure 10b, and $86 \%$ and $14 \%$ for 3 (solid line in Figure 11b). Note, that these numbers were obtained from original samples (before heating). Different volumes of residual HS fractions and invariable gap between the temperature curves $\chi T$ in Figure $10\left(\Delta \chi T \approx 0.5 \mathrm{~cm}^{3} \cdot \mathrm{K} \cdot \mathrm{mol}^{-1}\right.$ between the datasets $(\Delta)$ and $(\bigcirc)$ speak in favor of phase fractionation due to migration of solvent molecules. Similar fractionation was observed in [Fe(sal 2 -trien)][Ni(dmit $\left.)_{2}\right]$ structures [34-38]. Though the dihedral angle between the two phenoxy groups in $\left[\mathrm{Fe}(\mathrm{III})\left(\mathrm{sal}_{2} \text {-trien) }\right]^{+}\right.$at $100 \mathrm{~K}$ corresponds to the LS state $\left(73.24(4)^{\circ}\right.$, Figure $\left.3 \mathrm{~b}\right)$, the diffraction data might not resolve $\sim 20 \% \mathrm{HS}$ fraction. The TG-DSC curves in Figures S2 and S3 demonstrated more pronounced mass change at $93^{\circ} \mathrm{C}$, indicating a solvent loss in 2 in comparison with $1 \cdot \mathrm{MeOH}\left(126.7^{\circ} \mathrm{C}\right)$.
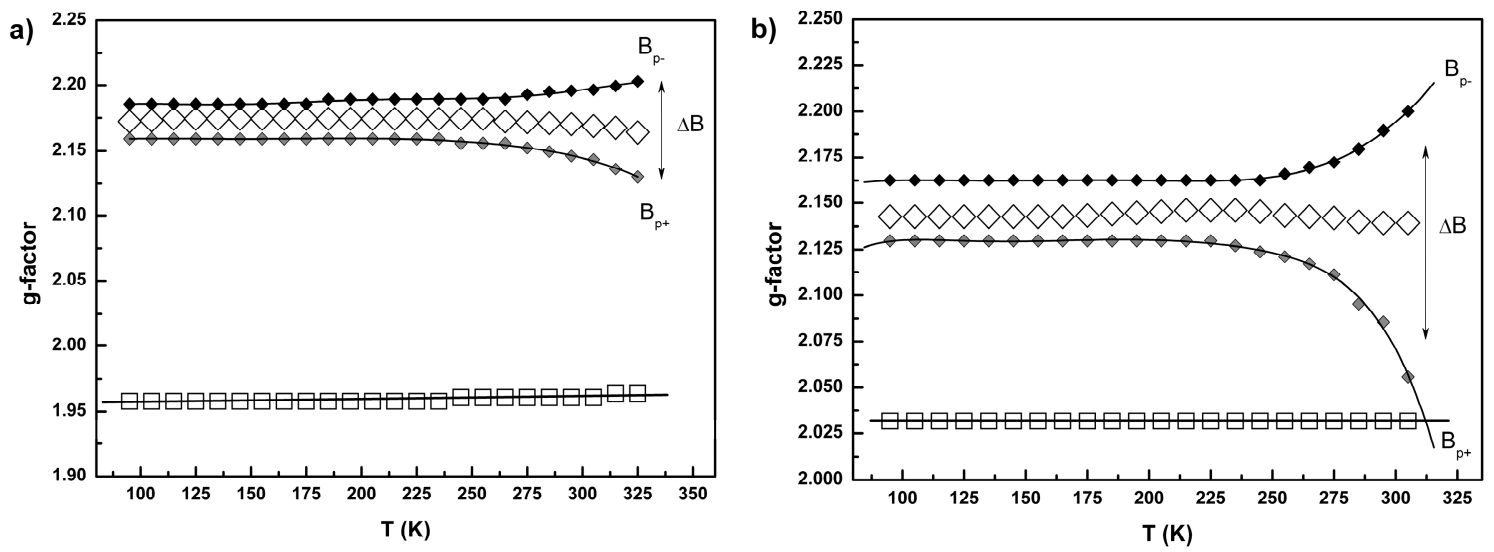

Figure 12. Temperature dependences of the g-parameters for $\mathbf{2}$ (a) and $\mathbf{3}$ (b) extracted from LS Fe(III) EPR signal while measurements in heating regime: $g_{\perp}(\diamond), g_{\mid}(\square)$. Solid lines connecting squares $(\boldsymbol{\square})$ fit the positions of the peaks $B_{\mathrm{p}+}$ and $B_{\mathrm{p}-}$ for simulation the partial spectral line corresponding to $g_{\perp}$, $\Delta B=B_{\mathrm{p}+}-B_{\mathrm{p}-}$.

The concentration of LS Fe(III)(sal ${ }_{2}$-trien) complexes in 2 and 3 was also verified by EPR. The measurements were carried out on the same samples that had passed through SQUID experiments. The absolute values, $I_{\mathrm{EPR}}$, at $100 \mathrm{~K}$ were found close to $2 / 3$ of the theoretical estimate to within $\sim 20 \%$ accuracy. The relative intensities $I_{\mathrm{EPR}}(\mathrm{T}) / I_{\mathrm{EPR}}(100 \mathrm{~K})$ plotted in Figures 10 and 11 (right ordinate axes) were obtained in the heating regime. In the range 95-325 K respective spin concentration of LS $\mathrm{Fe}(\mathrm{III})$ decreased with the temperature to $60 \%$ of its original value for 2 , and to $70 \%$ within $95-305 \mathrm{~K}$ range for 3. Temperature evolution of the lineshapes is shown in the Figures S7 and S8. The extracted $g$-parameters are presented in Figure 12 ((a) for $\mathbf{2}$ and (b) for $\mathbf{3})$. The character of anisotropy, as well as the weak temperature dependence, were discussed earlier for $1 \cdot \mathrm{MeOH}$. A common peculiar feature, axial anisotropy, was described by two parameters $g_{1}=g_{2}=g_{\perp}$ and $g_{3}=g_{\mid}$।. At $95 \mathrm{~K}$ they were $2.172(3)$ and 1.957(8) for 2, and 2.142(6) and 2.031(6) for 3. As the complexes underwent a thermal SCO, the EPR signal broadened, while the $g$-parameters remained unchanged. A partial peak-to-peak linewidth, $\Delta B$, corresponding to $g_{\perp}$ component was extracted and analyzed as a function of temperature like it had been done for $1 \cdot \mathrm{MeOH}$. The guiding lines for $B_{\mathrm{p}+}$ and $B_{\mathrm{p}-}$ are shown in Figure 12 .

The $\Delta B$ values at $100 \mathrm{~K}$ for 2 and 3 equaled $43.0 \mathrm{G}$ and $45.3 \mathrm{G}$, which was broader than $18.8 \mathrm{G}$ for $\mathbf{1} \cdot \mathrm{MeOH}$. Meanwhile, in 1· MeOH it quickly reached the value $46 \mathrm{G}$ at $\mathrm{HS} \mathrm{Fe}(\mathrm{III})$ concentration of $5 \%$. It was somewhat unclear, why at presence of $1 / 3(33 \%)$ complexes in HS state in 2 and 3 the EPR signal of $\mathrm{S}=1 / 2$ moments has the linewidth similar to that at $5 \%$ of $\mathrm{HS}$ complexes in $\mathbf{1} \cdot \mathrm{MeOH}$. Consensus becomes apparent if we assume spatial inhomogeneity. Spin-spin relaxation becomes ineffective if the fraction with $\mathrm{S}=1 / 2$ moments of LS Fe(III) and the HS fraction are separated in the cation layers. 
Besides that, insulating TCNQ dimers in $\mathbf{2}$ and $\mathbf{3}$ are unable to facilitate expanded interactions by mediating cross-relaxation via conduction electrons. At the same time, the LS fraction undergoes SCO transition, while the HS fraction remains unchanged. Indistinct $n / \mathrm{N}$ estimates together with less effective line broadening in $\mathbf{2}$, did not result in finding an appropriate correlation between EPR linewidth and concentration of Fe(III) ions in HS state. However, a credible linkage between line broadening and $\chi T$ growth was found in the system 3 . The transition was extrapolated by Boltzmann model. The exponential growth was superimposed by an ascending foothill segment (Figure S9). This feature arises because the thermal hysteresis is a kinetic effect, and spin states appear in result of cooperative interactions [52]. Spin concentration of $S=5 / 2, x$, was obtained by solving the equation at every temperature point of the measurement, $\chi_{\exp }(T)=(1-x) \cdot \chi_{1 / 2}{ }^{\text {theor }}+x \cdot \chi_{5 / 2}{ }^{\text {theor }}$, where $\chi_{1 / 2}$ theor and $\chi_{5 / 2}$ theor — theoretical values of the magnetic susceptibilities at $100 \%$ concentrations of LS or HS complexes, respectively. This procedure might seem arguable, because each data set was obtained in the different conditions, due to thermal irreversibility (spin fractionation). However, we believe that the linkage between EPR linewidth and spin concentration of $S=5 / 2$ moments remains valid, if the latter was extracted from the $\chi T$ data at heating in the first measurement cycle (data points $(\Delta)$ in Figure 11). Indeed, it follows from Figure 13 that the value $\Delta B_{\mathrm{LS}}$ increases proportionally to $n / \mathrm{N}$ above the threshold of $23 \%$. Similar dependence took place in $\mathbf{1} \cdot \mathrm{MeOH}$ right at the beginning of the reversible SCO transition. Hence, a broadening part of the dependence in $3, \Delta B \sim \mathrm{k} \cdot(n / \mathrm{N})$ (solid line in Figure 13a), where $\mathrm{k}=30.1 \mathrm{G} / \%$, occurs due to spin-spin relaxation. This contribution above the threshold is induced by thermally activated HS complexes with $S=5 / 2$, homogeneously appearing inside the LS fraction. For reference, in Figure S10 we present the temperature dependences $\Delta B_{\mathrm{LS}}(T)$ in 2 and 3 with respective fitting parameters in Table S4. The threshold is consistent with spatial in homogeneity of a spin ensemble, when spin probes of $S=1 / 2$ do not exist inside the intact fraction of $S=5 / 2$ moments.

The residual (intact) HS fraction remains spatially separated. EPR spectra from Fe(III) ions in the HS state in $\mathbf{2}$ and $\mathbf{3}$ are shown in Figure S8. Very weak temperature dependences of $g$-factor with $g=5.6(0)$ at $300 \mathrm{~K}$ were observed for 2, and with $g=4.06$ - for 3, respectively. Line broadening in the $\mathrm{SCO}$ range, $\Delta B_{\mathrm{HS}}(T)$, is shown in Figure $13 \mathrm{~b}$. The linewidth was found to follow a linear dependence $\Delta B_{\mathrm{HS}}=\Delta \mathrm{B}^{\mathrm{HS}}{ }_{0}+\mathrm{k}_{\mathrm{HS}} \cdot T$, where $\Delta \mathrm{B}^{\mathrm{HS}}{ }_{0}=5.66 \cdot 10^{2} \mathrm{G}$, and $\mathrm{k}_{\mathrm{HS}}=1.7 \mathrm{G} / \mathrm{K}$ for 2 , and $\Delta \mathrm{B}^{\mathrm{HS}}{ }_{0}=5.09 \cdot 10^{2} \mathrm{G}$, and $\mathrm{k}_{\mathrm{HS}}=0.91 \mathrm{G} / \mathrm{K}$ for 3 . A proportional broadening $\Delta B_{\mathrm{HS}}(T) \sim T$ was observed in the entire range of $\mathrm{SCO}$ in 3, whereas in 2 it begun at higher temperatures, which correlates with the data in Figure 12a and in further discussed Figure 14a.

An assumption of a phase fractionation, promoted by a solvent loss, implies a partition of the total spin susceptibility to the fractional contributions and further analysis of their individual temperature behavior. The magnetic susceptibility of the LS phase in 2 was reconstructed by using the expression, $\chi_{\mathrm{LS}} T=\left(\chi_{\exp }(T)-y \cdot \chi_{5 / 2}{ }^{\text {theor }}\right) \cdot T /(1-y)$, where $y$ is the concentration of the moments $S=5 / 2$ in the HS phase. Similarly, the expression $\chi_{H S} T=\left(\chi_{\exp }(T)-(1-y) \cdot \chi_{1 / 2}{ }^{\text {theor }}\right) \cdot T / y$ described the contribution of the HS phase. Here we took $g=2.00$ and 2.17 for calculated values of $\chi_{1 / 2}{ }^{\text {theor }}$ and $\chi_{5 / 2}{ }^{\text {theor }}$, respectively. A comparative plot " $\chi_{\mathrm{LS}} T$ vs. $T$ " in Figure 14 demonstrates, that the thermal cycling affects a foothill domain of the SCO transition curve, leaving its steep slope unchanged. EPR line broadening correlates with the steep part, but remains insensitive to a foothill region (see also Figure S9). This is consistent with the threshold in 3 (Figure 13), that was attributed to the cooperative interactions [52]. The broadening is caused by spin-spin interactions between $S=1 / 2$ spin probes with magnetic moments $S=5 / 2$ in the neighboring $\mathrm{HS}$ [Fe(III)( $\mathrm{sal}_{2}$-trien) $]^{+}$complexes, which do not belong to the residual HS fraction (HS phase). After several cycles of measurements, the amount of $\left[\mathrm{Fe}(\mathrm{III})\left(\mathrm{sal}_{2} \text {-trien }\right)\right]^{+}$complexes, taking part in the SCO transition, approached 2/3 of total. 

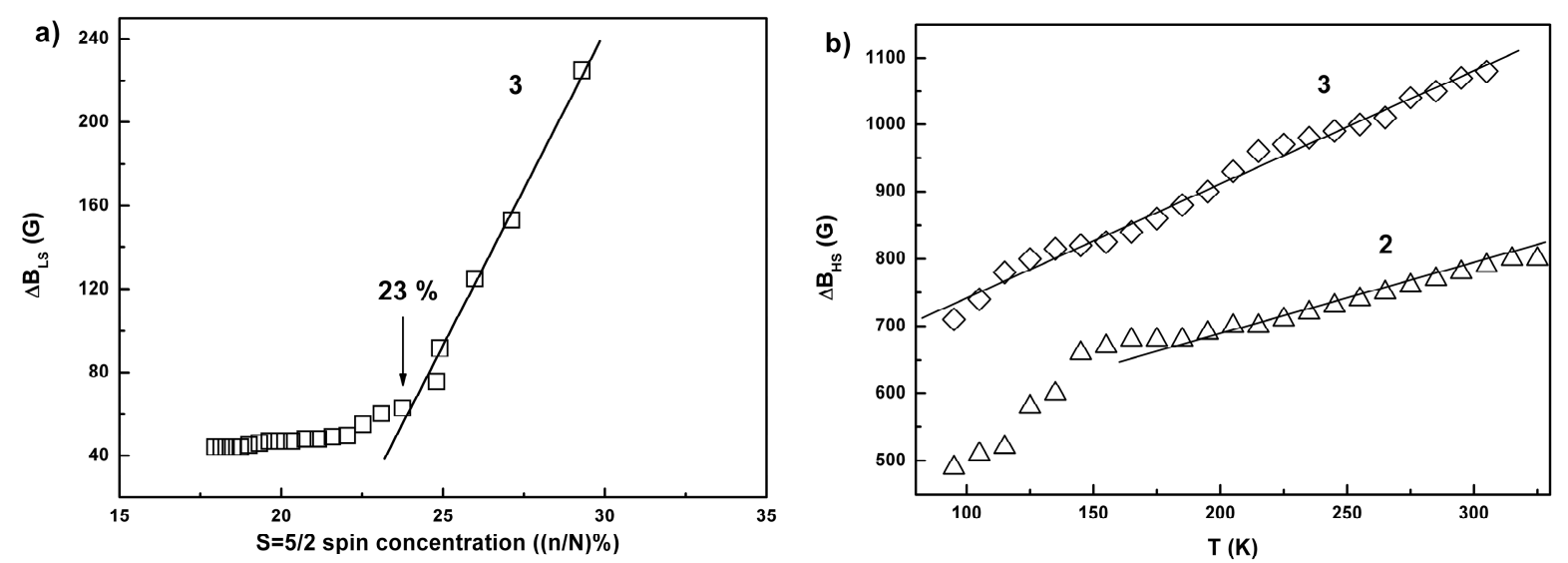

Figure 13. EPR linewidth, $\Delta B$, associated with $\mathrm{g}_{\perp}$ component of the total spectrum in 3 vs. concentration of the local moments $\mathrm{S}=5 / 2, n / \mathrm{N}(\%)(\mathbf{a})$. Solid line is the best fit function for $n / \mathrm{N}>23 \%$, $\Delta B_{\mathrm{LS}}=\Delta \mathrm{B}^{\mathrm{LS}}{ }_{0}+\mathrm{k}(n / \mathrm{N})$, where $\left|\Delta \mathrm{B}^{\mathrm{LS}}{ }_{0}\right|=6.60 \cdot 10^{2} \mathrm{G}$ and $\mathrm{k}=30.1 \mathrm{G} / \%$. Temperature dependences of the EPR linewidth for the high-spin moments, $\mathrm{S}=5 / 2, \Delta B_{\mathrm{HS}}(T)(\mathbf{b})$. Best-fit lines are given by the expression $\Delta B_{\mathrm{HS}}=\Delta B^{\mathrm{HS}}{ }_{0}+\mathrm{k}_{\mathrm{HS}} \cdot T$, where $\Delta \mathrm{B}^{\mathrm{HS}}{ }_{0}=5.66 \cdot 10^{2} \mathrm{G}$, and $\mathrm{k}_{\mathrm{HS}}=1.7 \mathrm{G} / \mathrm{K}$ for 2 , and $\Delta \mathrm{B}^{\mathrm{HS}}{ }_{0}=5.09 \cdot 10^{2} \mathrm{G}$, and $\mathrm{k}_{\mathrm{HS}}=0.91 \mathrm{G} / \mathrm{K}$ for 3 .
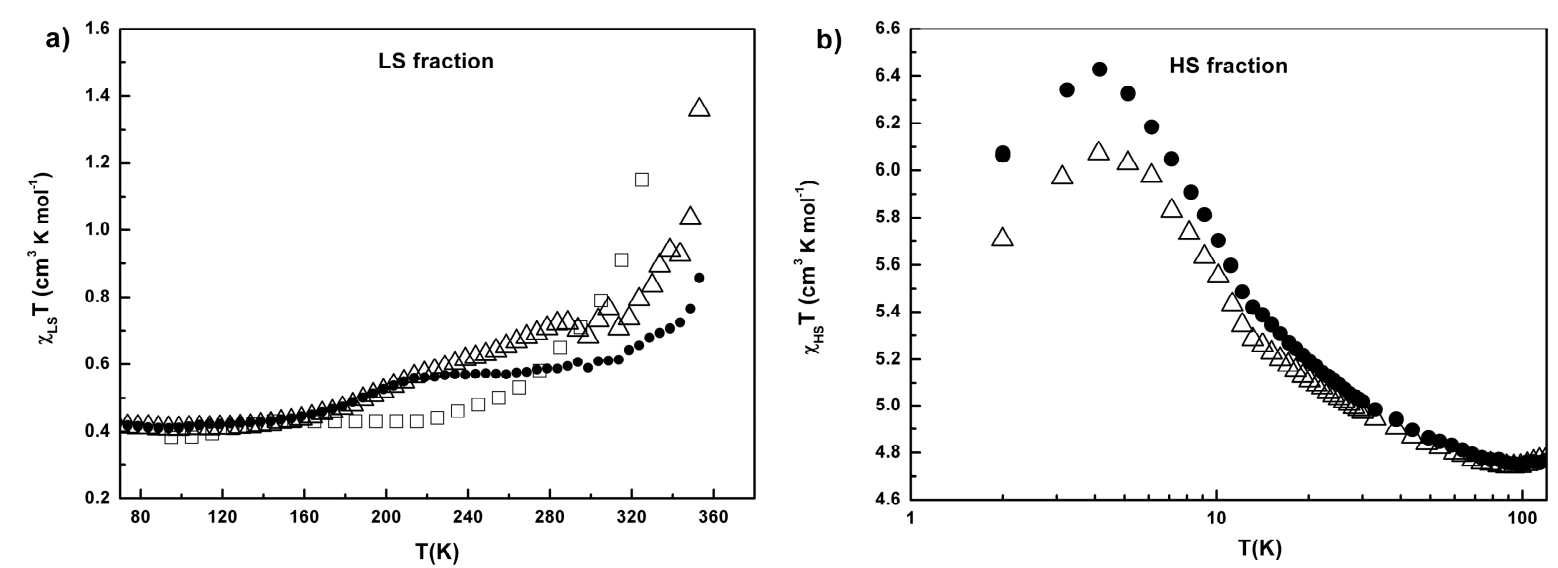

Figure 14. Temperature dependences of the product $\chi_{\mathrm{LS}} T$ for the LS (SCO) fraction in $\mathbf{2}$ (measurements in heating regime, cycle $1(\Delta)$, cycle $2(\bullet))(\mathbf{a})$. Temperature dependence of the EPR linewidth for $g_{\perp}$ component measured at heating in cycle $1(\square)$. Temperature dependences of the product $\chi_{\mathrm{HS}} T$ for the HS (residual) fraction $(\mathbf{b})$.

The total spin response $\chi T$ of 2 demonstrated unusual peaks at $T=4.11 \mathrm{~K}$ shown in Figure 10. System 3 also showed a significant growth of $\chi T$, though with no maximum, at temperatures $T<10 \mathrm{~K}$ (Figure 11). In this study, we attributed the observed peaks to the HS phase, $\chi_{\mathrm{HS}} T$, as shown in Figure 14b. We incline to discuss their ferromagnetic nature rather than metastable high spin trapping. Our opinion is based on the reasoning below.

Enhancement of a spin response at the low temperatures is often a sign of a thermal-induced metastable spin-state trapping (TIESST) [53]. Indeed, some mononuclear Fe(III) complexes, especially those with two-step spin-crossover, exhibit a metastable spin-state HS* emerging after thermal quench from the true HS state of a complete SCO transition. A key feature is the rate of cooling, which determines the amount of quenched fraction. A drop of $\chi_{\mathrm{HS}^{*}}$ T to the original LS level is, in fact, a relaxation of a metastable phase, while heating above the temperature, that corresponds to a respective energy barrier. A width of the transition depends on a heating rate, and usually consists tens of degrees in the transition range from 50 to $100 \mathrm{~K}$ [48]. A distinct feature of TIESST phase is the butte-like shape 
of the $\chi T$ curve, where the flat top may reach $\sim 50 \%$ of the total HS response, depending on a freezing rate. Here are the details, that contradict a mechanism of quenched HS* spin-state for 2: (1) gradual refrigeration down to $2.0 \mathrm{~K}$ took $5 \mathrm{~h}$ (including measurement time), which is $\sim 100$ times slower than the flash freezing in SQUID chamber; (2) the difference $\left(\chi_{\mathrm{HS}} T-\chi_{\mathrm{LS}} T\right)$ at maximum exceeded $100 \%$ of the $\chi_{\mathrm{LS}} T$ gain at $353 \mathrm{~K}$; (3) $\chi_{\mathrm{HS}} \mathrm{T}$ curves had no plateau and further relaxation drop, associated with decaying HS*spin-state; (4) gradual $50 \%$ decrease of $\chi_{\mathrm{HS}} \mathrm{T}$ between 4 and $10 \mathrm{~K}$ was unlikely caused by released dynamics (thermal relaxation) of sal $_{2}$-trien ligand; (5) maximum value of $\chi T$ in Figure $14 \mathrm{~b}$ did grow at cycle 2, whereas LS phase has diminished. However, since the complete SCO transition has not been reached, we cannot reject this scenario completely. Importantly, the TIESST mechanism does not imply magnetic coupling in the HS* system.

The alternative scenario suggests the magnetic exchange interactions in the HS phase. A maximum in $\chi T$ curve at helium temperatures is a characteristic feature of ferromagnetic or ferrimagnetic coupling in many molecular magneto-active systems, including HS Fe(III) complexes [52,54]. Ferromagnetic interactions were also found in numerous TCNQ based compounds with metallo-complex counerions [55]. Ferro- and ferrimagnetic coupling was reported for networks of transition metals, bridged by $\mathrm{TCNQ}^{-1}$ radicals $M(\mathrm{TCNQ})_{2}(M=\mathrm{Mn}, \mathrm{Fe}, \mathrm{Co}, \mathrm{Ni})$, among which was the compound $\mathrm{Mn}(\mathrm{TCNQ})_{2}$ with $T_{\mathrm{c}}=44 \mathrm{~K}[56,57]$.

In the crystal field approach, the structural characteristics of $\mathbf{1} \cdot \mathrm{MeOH}, \mathbf{2}$ and $\mathbf{3}$ deny exchange coupling between the magnetic moments of $\mathrm{Fe}(\mathrm{III})$ in neighboring complexes. Moreover, the shortest distances $d_{\mathrm{Fe}-\mathrm{Fe}}=7.070 \AA(350 \mathrm{~K}, \mathbf{1} \cdot \mathrm{MeOH})$ and $7.729 \AA(325 \mathrm{~K}, 2)$ are not sufficient for the effective spin-spin relaxation via dipole-dipole mechanism. Therefore, magnetic and resonance behavior of the $\mathrm{Fe}(\mathrm{III})$ magnetic moments, found in the current study, implies the key role of TCNQ molecules as a mediator. Schematic structural arrangements of the TCNQ molecules and [Fe( $\mathrm{sal}_{2}$-trien) $]^{+}$complexes in $\mathbf{1} \cdot \mathrm{MeOH}(\mathrm{A})$ and $\mathbf{2}$ (B) are shown in Figure 15. Dotted lines represent short contacts N... N, C...C, having distances less than the sum of their van der Waals radii including effect of a high spin $\mathrm{Fe}$ dilation. In $1 \cdot \mathrm{MeOH}$ at ambient conditions the distances $\mathrm{N}_{\text {amine }} \ldots \mathrm{N}_{\mathrm{CN}}$ were $3.128 \AA(\mathrm{N} 4, \mathrm{~N} 8 \mathrm{~T})$, $3.226 \AA(\mathrm{N} 4, \mathrm{~N} 5 \mathrm{~T}), \mathrm{N}_{\text {imine }} . . \mathrm{N}_{\mathrm{CN}}(\mathrm{N} 1, \mathrm{~N} 5 \mathrm{~T})-3.292 \AA$. Short contacts allow the exchange interactions. In the Ligand Field Theory (LFT), $\pi$ bonding between $d$-orbitals of transition metal in octahedral symmetry $t_{2 g}\left(d_{x y}, d_{y z}, d_{x z}\right)$ and $p(\pi)$ orbitals of the ligand takes place and significantly diminishes a total energy. In [Fe(sal 2 -trien) $]^{+}$complexes $\pi$ bonding is expected along OY axes (N1-Fe1-N2): $\mathrm{p}(\pi)_{\text {imine }}-\mathrm{d}_{\mathrm{yz}}-\mathrm{p}(\pi)_{\text {imine. }}$. Hybridization due to overlapping induces a local spin density on the ligand. In turn, non-bonding ligand orbitals of $\mathrm{N}_{\mathrm{amine}}$ and $\mathrm{N}_{\text {imine }}$ overlap with valence $\pi$ orbitals of $\mathrm{TCNQ}_{2}{ }^{-}$ $(\mathbf{1} \cdot \mathrm{MeOH})$ or SOMO $\pi^{*}$ orbitals of $\mathrm{CN}$ group in TCNQ ${ }^{\bullet-}$ radical (2). Thus, an interplay between $\pi$ bonding and intramolecular distortion could be the driving force for the exchange coupling. Note that that the acetonitrile molecule in $\mathbf{2}$ acts as an "anchor" due to short contact with $\mathrm{N}_{\text {amine }}(\mathrm{N} 3$, Figure 15B). Therefore, the solvent removal may release the distortions. However, a key role belongs to the electrons in the TCNQ sublattice. Hopping electrons of semiconducting TCNQ layers in 1. $\mathrm{MeOH}$ could serve as an efficient spin reservoir for cross relaxation between $S=1 / 2$ and $S=5 / 2$ local moments (Figure 15A). High conductivity along TCNQ stacks is capable to provide long-range spin-spin interactions. Localized spins of adjacent radicals $\mathrm{TCNQ}^{\bullet-}$ in weakly conducting compounds 2 and 3 suggest intrinsic interactions in the form of singlet-triplet splitting or exchange coupling. Taking into consideration $\pi$-stacking between phenoxy groups of neighboring ligands in Figure 15B, one can consider an alternating spin chain with the units [-1/2-1/2-1/2-1/2-], [-1/2-1/2-1/2-5/2-], or $[-5 / 2-1 / 2-1 / 2-5 / 2-]$ appearing upon passing the SCO transition. There were several drawbacks. We could not simulate the temperature dependences in Figure $14 \mathrm{~b}$ by a Heisenberg model for the individual four spin unit with two exchange constant $\mathrm{J}_{1}, \mathrm{~J}_{2}$ and one ZFS parameter $D$. We also did not find a coercivity in magnetization curves in Figures 11 and 12. Though the latter can be understood, as the measurements were performed before heating-cooling cycles. 

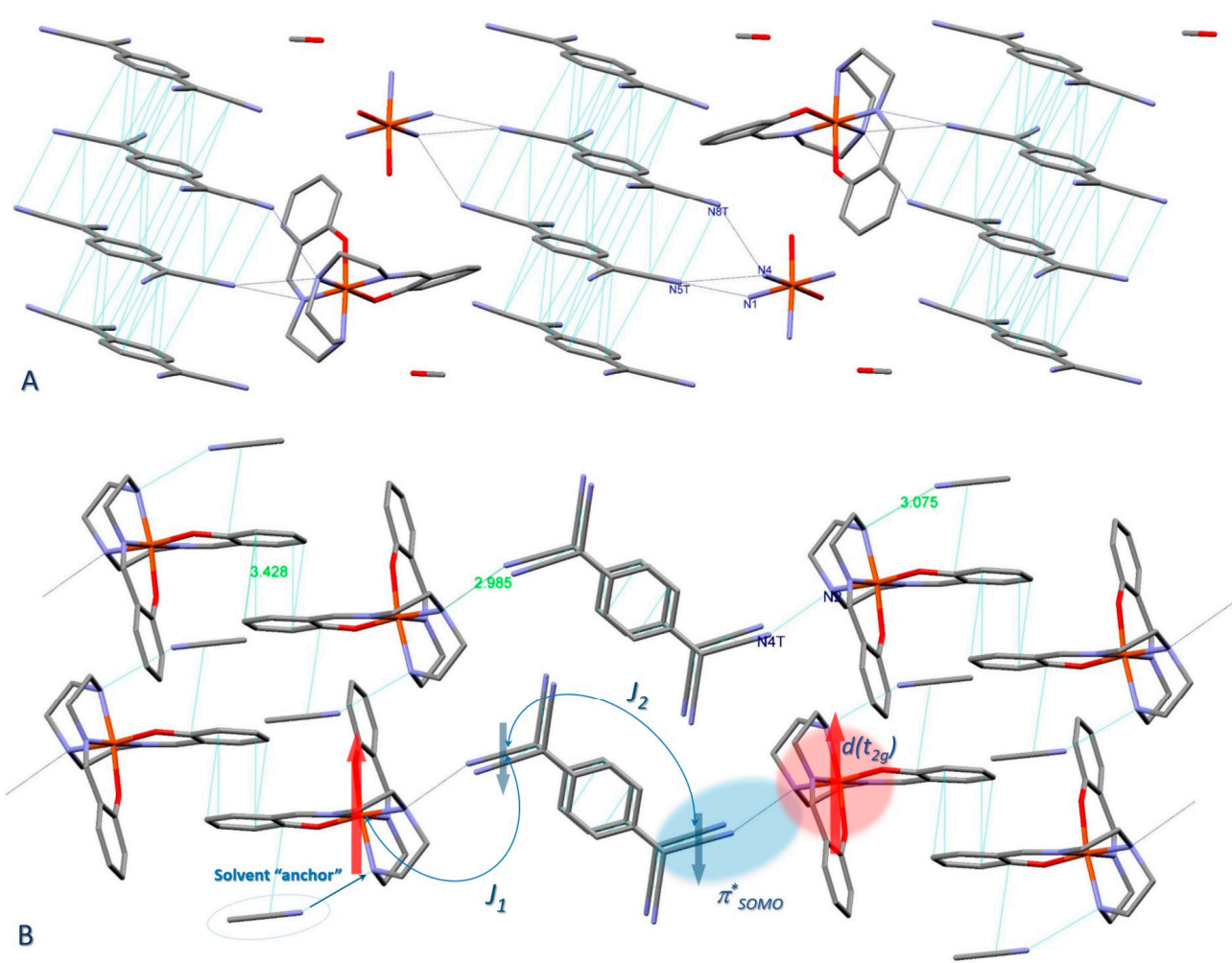

B

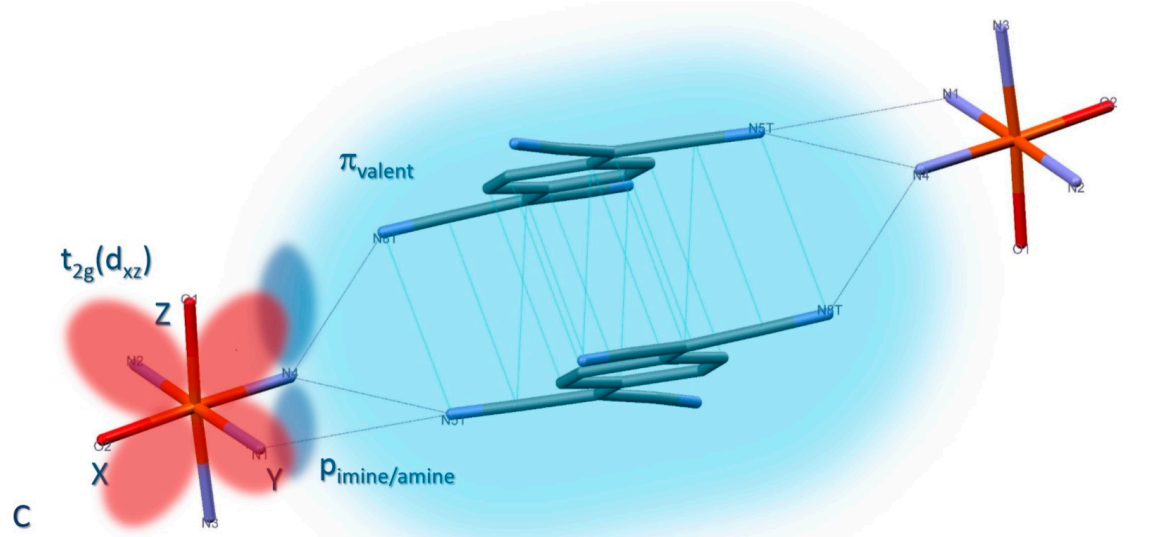

Figure 15. Schematic structural arrangements of the TCNQ molecules and $\left[\mathrm{Fe}\left(\mathrm{sal}_{2} \text {-trien }\right)\right]^{+}$cation complexes in 1. MeOH (A) and 2 (B). Dotted lines represent N... N, C. . C short contacts of less than the sum of the van der Waals radii; (C) Mutual arrangement of coordination Fe(III) octahedra with neighbor TCNQ units II in 1.MeOH. Orbitals are presented schematically.

Thus, the discussion of physical properties in this study was extended with somewhat hypothetical consideration of fundamental mechanisms. We believe, that holistically, this will draw attention to the important aspects of spin-spin interactions and electronic transport in [Fe(III)(sal 2 -trien)](TCNQ) $(\mathbf{1} \cdot \mathrm{MeOH})$ system as well as an interplay between ferro/ferrimagnetic coupling and SCO in [Fe(III)(sal ${ }_{2}$-trien)](TCNQ) $(2,3)$. While the first compound has a record conductivity up-to-date and reversible SCO transition, the compound [ $\mathrm{Fe}(\mathrm{III})\left(\mathrm{sal}_{2}\right.$-trien)](TCNQ) $\cdot \mathrm{CH}_{3} \mathrm{CN}$ is the first system, where ferromagnetic coupling was triggered by the SCO transition. In other words, in the system [Fe(III)(sal ${ }_{2}$-trien)](TCNQ) $)_{n}$ switchable magnetic moments of isolated metallo-complexes coexist and interact with spin system of organic network in full or fractional reduction state. In turn, the organic network allows electronic/spin transport. The fact that the spin interactions are switchable, makes this conducting system a prospective candidate for molecular spintronics. 


\section{Materials and Methods}

General remarks: LiTCNQ and $\left[\mathrm{Fe}\left(\mathrm{sal}_{2}\right.\right.$-trien) $]\left(\mathrm{NO}_{3}\right) \cdot 1.5 \mathrm{H}_{2} \mathrm{O}$ were obtained according to the literature procedures $[19,58]$. All other reagents and solvents were commercial products.

\subsection{Synthesis}

$\left[\mathrm{Fe}\left(\mathrm{sal}_{2}\right.\right.$-trien $\left.)\right](\mathrm{TCNQ})_{2} \cdot \mathrm{CH}_{3} \mathrm{OH}(\mathbf{1} \cdot \mathrm{MeOH})$ was synthesized under argon atmosphere by mixing hot solutions of TCNQ $(0.102 \mathrm{~g}, 0.5 \mathrm{mmol})$ in $10 \mathrm{~mL}$ of acetonitrile, LiTCNQ $(0.106 \mathrm{~g}, 0.5 \mathrm{mmol})$ and [Fe(sal 2 -trien) $]\left(\mathrm{NO}_{3}\right) \cdot 1.5 \mathrm{H}_{2} \mathrm{O}(0.232 \mathrm{~g}, 0.5 \mathrm{mmol})$, each in a mixture of acetonitrile/methanol $(10 / 5 \mathrm{~mL})$. The resulting solution was placed in a refrigerator overnight. Black shiny plate crystals of $1 \cdot \mathrm{MeOH}$ were formed. They were collected and washed with cold methanol and dried on air. Yield: $0.253 \mathrm{~g}$ (59\%). Elemental analysis calcd. (\%) for 1· $\mathrm{MeOH}\left(\mathrm{C}_{45} \mathrm{H}_{36} \mathrm{FeN}_{12} \mathrm{O}_{3}\right)$ : C 63.68, H 4.27, N 19.8, O 5.66; found (\%): C 63.21, H 4.50, N 19.54, O 5.85.

[ $\mathrm{Fe}\left(\mathrm{sal}_{2}\right.$-trien)]TCNQ$\cdot \mathrm{CH}_{3} \mathrm{CN}$ (2). Dark purple platelet-like crystals of 2 were obtained by recrystallization of $\mathbf{3}$ from acetonitrile. Yield: $70.0 \%$. Elemental analysis (\%): calc. for $\mathbf{2}\left(\mathrm{C}_{34} \mathrm{H}_{31} \mathrm{FeN}_{9} \mathrm{O}_{2}\right)$ : C 62.49, H 4.78, N 19.29, O 4.9; found (\%): C 62.24, H 4.50, N 18.96, O 5.27.

$\left[\mathrm{Fe}\left(\mathrm{sal}_{2}\right.\right.$-trien) $](\mathrm{TCNQ})_{2} \cdot \mathrm{H}_{2} \mathrm{O}$ (3) was obtained by mixing hot solutions $\left[\mathrm{Fe}\left(\mathrm{sal}_{2}\right.\right.$-trien) $]\left(\mathrm{NO}_{3}\right)$ $\cdot 1.5 \mathrm{H}_{2} \mathrm{O}(0.232 \mathrm{~g}, 0.5 \mathrm{mmol})$ and LiTCNQ $(0.106 \mathrm{~g}, 0.5 \mathrm{mmol})$, each in $10 \mathrm{~mL}$ of methanol. The resulting solution was placed in the refrigerator overnight. Microcrystals were formed, which were collected, washed with ether and dried on air. Yield: $0.270 \mathrm{~g}$ (85\%). Elemental analysis calcd. (\%) for 3 $\left(\mathrm{C}_{32} \mathrm{H}_{30} \mathrm{FeN}_{8} \mathrm{O}_{3}\right)$ : C60.96, H4.80, N17.77, O7.60; found (\%): C 60.94, H 4.54, N 17.51, O 7.97.

\subsection{Thermogravimetric Analysis}

The thermogravimetric analysis was performed in argon atmosphere with a heating rate $5.0^{\circ} \mathrm{C} \cdot \mathrm{min}^{-1}$ using a NETZSCH STA $409 \mathrm{C} /$ QMS 403 thermal analyzer (NETZSCH-Gerätebau GmbH, Selb, Germany), which allows simultaneous thermogravimetry (TG), differential scanning calorimetry (DSC) and mass-spectrometry measurements, which allows simultaneous thermogravimetry (TG), differential scanning calorimetry (DSC) and mass-spectrometry measurements.

\subsection{X-ray Crystallography}

Single crystal X-ray diffraction experiments were carried out on a Bruker SMART APEX2 CCD diffractometer (Bruker AXS Advanced X-ray Solutions $\mathrm{GmbH}$, Karlsruhe, Germany) (for 1-MeOH at $100,220 \mathrm{~K}$ and 2 at $100 \mathrm{~K}$ ) and an Oxford Diffraction Gemini-R CCD diffractometer (Oxford Diffraction, Oxford, Oxfordshire, United Kingdom) [for all other temperatures, $\lambda(\mathrm{MoK} \alpha)=0.71073 \AA$, graphite monochromator, $\omega$-scan mode]. Multi temperature experiment procedure was used without control of cooling/warming rate; the average rate was roughly estimated as $2-4 \mathrm{~K} / \mathrm{min}$. Data collection for $\mathbf{1} \cdot \mathrm{MeOH}$ and 1 proceeded during $24 \mathrm{~h}$ at each temperature. Crystal of $\mathbf{1} \cdot \mathrm{MeOH}$ had begun to lose solvent at the end of the $340 \mathrm{~K}$ experiment; in this reason some latest $\mathrm{X}$-ray frames were excluded from the data list for correct refinement of the solvate structure. Then the crystal was warmed to $350 \mathrm{~K}$ and kept at this temperature during one day before data collection to obtain the new phase 1 totally free of solvent. The structures were solved by the direct method and refined by the full-matrix least-squares technique against $F^{2}$ in an anisotropic approximation for all non-hydrogen atoms. Hydrogen atoms were localized from the Fourier synthesis of the electron density and refined in the isotropic approximation. $\mathrm{MeOH}$ sites in $\mathbf{1} \cdot \mathrm{MeOH}$ were finally refined as fully occupied at 295 and $340 \mathrm{~K}$ though occupancy refinement gave values of 0.988(4) and 0.956(6), respectively. All calculations were performed using SHELXTL PLUS 5.0 and SHELX-2016 program packages [59]. Selected crystallographic data and refinement parameters are given in Table 3. The full data of studies are available at the Cambridge Crystallographic Data Centre. Distortion of the lattice due to solvent loss transforms acute unit cell of $\mathbf{1} \cdot \mathrm{MeOH}$ into obtuse one for $\mathbf{1}$, the latter is given in non-standard setting both in Table 3 and cif-files for direct comparison of the structure data. 
Table 3. Crystal structure and refinement data for $\mathbf{1} \cdot \mathrm{MeOH}, \mathbf{1}$ and $\mathbf{2}$.

\begin{tabular}{|c|c|c|c|c|c|c|c|}
\hline Parameter & $\begin{array}{c}1 \cdot \mathrm{MeOH} \\
100 \mathrm{~K}\end{array}$ & $\begin{array}{c}1 \cdot \mathrm{MeOH} \\
220 \mathrm{~K}\end{array}$ & $\begin{array}{c}1 \cdot \mathrm{MeOH} \\
295 \mathrm{~K}\end{array}$ & $\begin{array}{c}1 \cdot \mathrm{MeOH} \\
340 \mathrm{~K}\end{array}$ & $\begin{array}{c}1 \\
350 \mathrm{~K}\end{array}$ & $\begin{array}{c}1 \\
385 \mathrm{~K}\end{array}$ & $\begin{array}{c}1 \\
325 \mathrm{~K}\end{array}$ \\
\hline Cell setting & triclinic & triclinic & triclinic & triclinic & triclinic & triclinic & triclinic \\
\hline Formula & $\mathrm{C}_{45} \mathrm{H}_{36} \mathrm{FeN}_{12} \mathrm{O}_{3}$ & $\mathrm{C}_{45} \mathrm{H}_{36} \mathrm{FeN}_{12} \mathrm{O}_{3}$ & $\mathrm{C}_{45} \mathrm{H}_{36} \mathrm{FeN}_{12} \mathrm{O}_{3}$ & $\mathrm{C}_{45} \mathrm{H}_{36} \mathrm{FeN}_{12} \mathrm{O}_{3}$ & $\mathrm{C}_{44} \mathrm{H}_{32} \mathrm{FeN}_{12} \mathrm{O}_{2}$ & $\mathrm{C}_{44} \mathrm{H}_{32} \mathrm{FeN}_{12} \mathrm{O}_{2}$ & $\mathrm{C}_{44} \mathrm{H}_{32} \mathrm{FeN}_{12} \mathrm{O}_{2}$ \\
\hline Molecular weight & 848.71 & 848.71 & 848.71 & 848.71 & 816.67 & 816.67 & 816.67 \\
\hline Crystal size (mm) & $0.40 \times 0.20 \times 0.14$ & $0.40 \times 0.20 \times 0.14$ & $0.39 \times 0.23 \times 0.07$ & $0.55 \times 0.19 \times 0.06$ & $0.55 \times 0.19 \times 0.06$ & $0.39 \times 0.23 \times 0.07$ & $0.55 \times 0.19 \times 0.06$ \\
\hline$\lambda(\operatorname{MoK} \alpha)(\AA)$ & 0.71073 & 0.71073 & 0.71073 & 0.71073 & 0.71073 & 0.71073 & 0.71073 \\
\hline Space group, $Z$ & $P \overline{1}, 2$ & $P \overline{1}, 2$ & $P \overline{1}, 2$ & $P \overline{1}, 2$ & $P \overline{1}, 2$ & $P \overline{1}, 2$ & $P \overline{1}, 2$ \\
\hline$a(\AA)$ & $8.9571(5)$ & $8.9675(3)$ & $8.9616(2)$ & $8.9838(3)$ & $8.8932(5)$ & $8.8948(3)$ & $8.9218(2)$ \\
\hline$b(\AA)$ & $13.1036(7)$ & $13.2483(5)$ & $13.3489(2)$ & $13.4223(5)$ & $12.9755(8)$ & $13.0374(7)$ & $12.9832(4)$ \\
\hline$c(\AA)$ & $17.4234(9)$ & $17.4794(7)$ & $17.5163(3)$ & $17.5869(5)$ & $17.6089(5)$ & $17.7142(7)$ & $17.6134(4)$ \\
\hline$\alpha\left(^{\circ}\right)$ & $89.338(1)$ & $89.1589(8)$ & $88.976(2)$ & $88.985(3)$ & $91.234(4)$ & $91.106(4)$ & $91.356(2)$ \\
\hline$\beta\left(^{\circ}\right)$ & $85.101(1)$ & $85.2423(8)$ & $85.3650(10)$ & $85.425(3)$ & $86.922(4)$ & $87.062(3)$ & $86.696(2)$ \\
\hline$\gamma\left({ }^{\circ}\right)$ & $78.027(1)$ & $78.3151(8)$ & $78.525(2)$ & $78.782(3)$ & $82.757(5)$ & $82.846(4)$ & $82.570(2)$ \\
\hline Cell volume $\left(\AA^{3}\right)$ & 1993.2(2) & $2026.58(13)$ & $2046.83(7)$ & 2073.54(12) & 2012.01(18) & $2034.87(15)$ & 2018.73(9) \\
\hline$\rho\left(\mathrm{g} / \mathrm{cm}^{3}\right)$ & 1.414 & 1.391 & 1.377 & 1.359 & 1.348 & 1.333 & 1.344 \\
\hline$\mu, \mathrm{cm}^{-1}$ & 4.38 & 4.31 & 4.26 & 4.21 & 4.29 & 4.24 & 4.28 \\
\hline Refls collected/unique & $24,684 / 10,591$ & $21,590 / 10,764$ & $22,180 / 10,116$ & $20,254 / 10,910$ & $16,091 / 9254$ & $21,019 / 10,054$ & $17,015 / 9203$ \\
\hline$R_{\text {int }}$ & 0.0552 & 0.0371 & 0.0139 & 0.0515 & 0.0217 & 0.0353 & 0.0178 \\
\hline$\theta_{\max }\left({ }^{\circ}\right)$ & 29.0 & 29.0 & 28.3 & 31.1 & 28.3 & 28.3 & 28.3 \\
\hline Refls with $[I>2 \sigma(I)]$ & 7166 & 7057 & 8542 & 7150 & 5480 & 4017 & 6038 \\
\hline Parameters refined & 562 & 562 & 560 & 560 & 538 & 538 & 538 \\
\hline Final $R_{1}, w R_{2}[I>2 \sigma(I)]$ & $0.0496,0.1022$ & $0.0426,0.0920$ & $0.0348,0.0884$ & $0.0597,0.1327$ & $0.0613 / 0.1386$ & $0.0699,0.1311$ & $0.0569,0.1244$ \\
\hline Goodness-of-fit & 1.011 & 1.000 & 1.002 & 1.000 & 1.006 & 1.003 & 1.003 \\
\hline Residual el. density $\left(\mathrm{e} \cdot \AA^{-3}\right)$ & $0.502 /-0.633$ & $0.349 /-0.482$ & $0.279 /-0.219$ & $1.109 /-0.331$ & $0.489 /-0.621$ & $0.495 /-0.349$ & $0.559 /-0.705$ \\
\hline CCDC reference & 1527039 & 1527040 & 1527042 & 1527041 & 1527043 & 1527044 & 1527045 \\
\hline
\end{tabular}


Table 3. Cont

\begin{tabular}{|c|c|c|c|c|c|c|c|}
\hline Parameter & $\begin{array}{c}1 \\
295 \mathrm{~K}\end{array}$ & $\begin{array}{c}1 \\
260 \mathrm{~K}\end{array}$ & $\begin{array}{c}1 \\
220 \mathrm{~K}\end{array}$ & $\begin{array}{c}2 \\
100 \mathrm{~K}\end{array}$ & $\begin{array}{c}2 \\
220 \mathrm{~K}\end{array}$ & $\begin{array}{c}2 \\
295 K\end{array}$ & $\begin{array}{c}2 \\
325 \mathrm{~K}\end{array}$ \\
\hline Cell setting & triclinic & triclinic & triclinic & triclinic & triclinic & triclinic & triclinic \\
\hline Formula & $\mathrm{C}_{44} \mathrm{H}_{32} \mathrm{FeN}_{12} \mathrm{O}_{2}$ & $\mathrm{C}_{44} \mathrm{H}_{32} \mathrm{FeN}_{12} \mathrm{O}_{2}$ & $\mathrm{C}_{44} \mathrm{H}_{32} \mathrm{FeN}_{12} \mathrm{O}_{2}$ & $\mathrm{C}_{34} \mathrm{H}_{31} \mathrm{FeN}_{9} \mathrm{O}_{2}$ & $\mathrm{C}_{34} \mathrm{H}_{31} \mathrm{FeN}_{9} \mathrm{O}_{2}$ & $\mathrm{C}_{34} \mathrm{H}_{31} \mathrm{FeN}_{9} \mathrm{O}_{2}$ & $\mathrm{C}_{34} \mathrm{H}_{31} \mathrm{FeN}_{9} \mathrm{O}_{2}$ \\
\hline Molecular weight & 816.67 & 816.67 & 816.67 & 653.53 & 653.53 & 653.53 & 653.53 \\
\hline Crystal size (mm) & $0.55 \times 0.19 \times 0.06$ & $0.55 \times 0.19 \times 0.06$ & $0.55 \times 0.19 \times 0.06$ & $0.13 \times 0.10 \times 0.08$ & $0.52 \times 0.28 \times 0.05$ & $0.52 \times 0.28 \times 0.05$ & $0.52 \times 0.28 \times 0.05$ \\
\hline$\lambda(\operatorname{MoK} \alpha)(\AA)$ & 0.71073 & 0.71073 & 0.71073 & 0.71073 & 0.71073 & 0.71073 & 0.71073 \\
\hline Space group, $Z$ & $P \overline{1}, 2$ & $P \overline{1}, 2$ & $P \overline{1}, 2$ & $P \overline{1}, 2$ & $P \overline{1}, 2$ & $P \overline{1}, 2$ & $P \overline{1}, 2$ \\
\hline$a(\AA)$ & $8.9230(2)$ & $8.8950(2)$ & $8.9120(2)$ & $7.6085(8)$ & $7.6695(4)$ & $7.7072(4)$ & $7.72945(18)$ \\
\hline$b(\AA)$ & $12.9439(3)$ & $12.8594(3)$ & $12.8379(3)$ & $14.2710(16)$ & $14.3596(5)$ & $14.3879(6)$ & $14.4016(4)$ \\
\hline$c(\AA)$ & $17.5498(3)$ & $17.4386(3)$ & $17.4233(4)$ & $16.0300(18)$ & $16.0693(5)$ & $16.1428(6)$ & $16.1913(6)$ \\
\hline$\alpha\left({ }^{\circ}\right)$ & $91.432(2)$ & $91.464(2)$ & $91.468(2)$ & $67.454(2)$ & $66.939(3)$ & $66.861(4)$ & $66.872(3)$ \\
\hline$\beta\left(^{\circ}\right)$ & $86.497(2)$ & $86.312(2)$ & $86.152(2)$ & $85.078(2)$ & $84.870(3)$ & $84.786(4)$ & $84.831(3)$ \\
\hline$\gamma\left({ }^{\circ}\right)$ & $82.430(2)$ & $82.310(2)$ & $82.220(2)$ & $76.296(2)$ & $76.089(4)$ & $75.980(4)$ & $75.969(2)$ \\
\hline Cell volume $\left(\AA^{3}\right)$ & $2004.44(7)$ & $1971.49(7)$ & $1969.41(8)$ & 1561.7(3) & $1580.51(11)$ & $1597.03(13)$ & $1608.02(9)$ \\
\hline$\rho\left(\mathrm{g} / \mathrm{cm}^{3}\right)$ & 1.353 & 1.376 & 1.377 & 1.390 & 1.373 & 1.359 & 1.350 \\
\hline$\mu, \mathrm{cm}^{-1}$ & 4.31 & 4.38 & 4.38 & 5.30 & 5.24 & 5.19 & 5.15 \\
\hline Refls collected/unique & $16,900 / 9137$ & $15,460 / 8994$ & $16,836 / 9234$ & $19,290 / 8302$ & $16,642 / 8648$ & $17,204 / 8850$ & $16,515 / 8763$ \\
\hline$R_{\text {int }}$ & 0.0165 & 0.0177 & 0.0171 & 0.0627 & 0.0179 & 0.0229 & 0.0220 \\
\hline$\theta_{\max }\left({ }^{\circ}\right)$ & 28.3 & 28.3 & 29.5 & 29.0 & 28.8 & 29.0 & 28.8 \\
\hline Refls with $[I>2 \sigma(I)]$ & 6665 & 6990 & 7080 & 6003 & 7172 & 6739 & 6104 \\
\hline Parameters refined & 538 & 538 & 538 & 423 & 426 & 426 & 426 \\
\hline Final $R_{1}, w R_{2}[I>2 \sigma(I)]$ & $0.0479,0.1080$ & $0.0427,0.0924$ & $0.0387,0.0877$ & $0.0391,0.0814$ & $0.0348,0.0776$ & $0.0406,0.0871$ & $0.0459,0.0953$ \\
\hline Goodness-of-fit & 1.003 & 1.004 & 1.001 & 1.007 & 1.006 & 1.005 & 1.001 \\
\hline Residual el. density $\left(\mathrm{e} \cdot \AA^{-3}\right)$ & $0.447 /-0.652$ & $0.387 /-0.548$ & $0.335 /-0.349$ & $0.487 /-0.448$ & $0.310 /-0.437$ & $0.312 /-0.443$ & $0.350 /-0.202$ \\
\hline CCDC reference & 1527046 & 1527047 & 1527048 & 1527049 & 1527050 & 1527051 & 1527052 \\
\hline
\end{tabular}




\subsection{Transport and Magnetic Measurements}

The dc resistivity measurements were performed on single crystals by a standard four-probe method with the current flow parallel to the TCNQ stacks (along the [110] direction) in the temperature range 78-300 K. Four annealed platinum wires (0.02 $\mathrm{mm}$ in diameter) were attached to a crystal surface by a graphite paste (Figure S1). This geometry is convenient for the test measurements to reveal the features in the temperature dependences of the resistance including measurement time. In the strongly anisotropic sample the measured value contains the mixture of both in-plane and out-of-plane components of the resistivity tensor, due to the current distributed non-uniformly through the sample cross section. This explains why we measured the resistivity tensor components separately in the control experiments. To measure in-plane anisotropy we applied Montgomery method [60] for the samples in the shape of thin plates, elongated in the direction of TCNQ stacks (typical sample shape is shown in the Figure S1). Therefore, by using two pairs of contacts attached to the plate corners on the long sides of the plate, we could measure two components of the resistivity tensor along and perpendicular to the of TCNQ stacks. To measure the out-of-plane resistivity tensor we applied the modified Montgomery method [61] on the sample with two pairs of contacts attached to the opposite sample surfaces.

Magnetic measurements were performed by using a Quantum Design MPMS-5-XL SQUID magnetometer (Quantum Design, San Diego, CA, USA). The static magnetic susceptibility $\chi(T)$ of the polycrystalline sample was measured at the magnetic fields $\mathrm{B}=0.1 \mathrm{~T}, 4.0 \mathrm{~T}$ at warming and cooling regimes in the temperature range of $2-400 \mathrm{~K}$. Field dependence of the magnetization $M(B)$ were obtained at $2.0 \mathrm{~K}$ after several scans over the field range from -5.0 to $+5.0 \mathrm{~T}$. The sample had been cooled to $2.0 \mathrm{~K}$ in a magnetic field $\mathrm{B}=4.0 \mathrm{~T}$. Then the measurements were performed at the decreasing field with a sign reversal to $-5.0 \mathrm{~T}$ and further increasing field to $+5.0 \mathrm{~T}$.

EPR spectra were recorded in the temperature range of $90-370 \mathrm{~K}$ on a standard homodyne X-band (9.4 GHz) Bruker ELEXSYS E580 FT/CW spectrometer (Bruker AXS GmbH, Karlshruhe, Germany). The temperature was set and stabilized at a rate of $0.5-5 \mathrm{~K} / \mathrm{min}$ with an accuracy of $0.1 \mathrm{~K}$ using a liquid nitrogen gas-flow cryostat. The spin contribution to the magnetic susceptibility was determined by the double integration of the EPR signal (Schumacher-Slichter method) under conditions for the field sweep $\delta \mathrm{B}_{\mathrm{sw}} \geq 10 \Delta \mathrm{B}(\Delta \mathrm{B}$ is the peak-to-peak EPR line width of the total spectrum). In this case, an error of the method for the Lorentz lineshape is $\sim 10 \%$. The pyrolytic coal product with $g=2.00283$ was used as the standard of a spin concentration.

\section{Conclusions}

We reported synthesis and physical properties (structure, transport, magnetic susceptibility, magnetization and electron paramagnetic resonance characteristics) of the series of three compounds incorporating $\mathrm{Fe}(\mathrm{III})$ cation complexes $\left[\mathrm{Fe}(\mathrm{III})\left(\mathrm{sal}_{2} \text {-trien) }\right]^{+}\right.$in the TCNQ network in a fractional/full reduction state:[Fe(III)( $\mathrm{sal}_{2}$-trien $\left.)\right](\mathrm{TCNQ})_{2} \cdot \mathrm{CH}_{3} \mathrm{OH}(\mathbf{1} \cdot \mathrm{MeOH}),\left[\mathrm{Fe}(\mathrm{III})\left(\mathrm{sal}_{2}\right.\right.$-trien) $](\mathrm{TCNQ}) \cdot \mathrm{CH}{ }_{3} \mathrm{CN}$ (2), and $\left[\mathrm{Fe}(\mathrm{III})\left(\mathrm{sal}_{2}\right.\right.$-trien)](TCNQ) $\cdot \mathrm{H}_{2} \mathrm{O}(3)$. Spin-crossover transition was found in all three systems regardless solvent molecules.

Highly conducting system $(\mathbf{1} \cdot \mathrm{MeOH})$ with $\sigma(300 \mathrm{~K})=5.4 \Omega^{-1} \cdot \mathrm{cm}^{-1}$ and narrow band gap $\Delta E=0.05 \mathrm{eV}$ revealed a reversible $\mathrm{SCO}$ transition at $410 \mathrm{~K}$. Resistivity and spin relaxation in the conducting tetradic TCNQ stacks were found sensitive to SCO but demonstrated qualitatively different behavior. Spin-spin relaxation between low-spin and high-spin moments of Fe(III) complexes took place via a spin reservoir of mobile electrons. Temperature evolution of the structural characteristics revealed the in-stack charge leveling and thermal hysteresis due to solvent loss.

Low conducting systems 2 and 3 demonstrated irreversible magnetic response and thermal hysteresis of SCO transition. Due to cooperative interactions, solvent loss led to the phase fractionation. The LS phase demonstrated SCO transition and revealed spin-spin interactions between low-spin and high-spin magnetic moments of Fe(III) ions. Residual HS phase discovered ferro(ferri)magnetic coupling at $T_{\mathrm{C}}=4.11 \mathrm{~K}$. 
We did consider the arguments, promoting presence of superexchange coupling between sal 2 -trien ligand and $\mathrm{CN}$ groups of TCNQ via $\mathrm{N}_{\text {amine }} / \mathrm{N}_{\text {imine }}$ short contacts. Switchable magnetic moments, ferromagnetic coupling, and low-dimensional conductivity make the realization of spin-dependent electron transport prospective in such systems.

Supplementary Materials: The following are available online, Figure S1: A crystal of complex 1.MeOH with the electrodes for measurement of conductivity, Figure S2: TG-DSC curves and mass spectra for 1.MeOH, Figure S3: TG-DSC curves and mass spectra for 2, Figure S4: The character of TCNQ overlap within the II-I-I-II tetrads (a) and between the tetrads (b) in $\mathbf{1} \cdot \mathrm{MeOH}$ at $100 \mathrm{~K}$, Figure S5: View of the structure 2 along a, Figure S6: The $\pi$... $\pi$ stacking in the pairs of cations in 2, Figure S7: Temperature evolution of the EPR lineshape for 2 and 3, Figure S8: EPR spectra for the compounds 1.MeOH (1), 2 (2) and 3 (3), Figure S9: Evolution of the $\chi T$ for 2 in the range of spin-crossover transition between the LS states, $S=1 / 2$, and the HS states, $S=5 / 2$, of Fe(III) ions, Figure S10: Best-fit curves for EPR linewidth broadening, $\Delta B(T)$, in 1·MeOH, 2 and 3, Table S1: The charges $(\delta)$ of TCNQ radical anions estimated from Kistenmacher's empirical formula, Table S2: Selected bond lengths $(\AA)$ and angles $\left({ }^{\circ}\right)$ in 1.MeOH and 1,Table S3: Selected bond lengths $(\AA)$ and angles $\left(^{\circ}\right)$ in 2, Table S4: Parameters of exponential fitting curves for the EPR linewidth data in Figure S10.

Acknowledgments: This work was supported by the Russian Foundation for Basic Research, project No. 14-03-00119 and Presidium of the Russian Academy of Sciences, project No. 15-17-2-17. The authors would like to thank K.A. Lyssenko for the X-ray experiments at $100 \mathrm{~K}$ and $220 \mathrm{~K}$ for $\mathbf{1} \cdot \mathrm{MeOH}$ and at $100 \mathrm{~K}$ for 2.

Author Contributions: A.I.K. synthesized the complexes; S.V.S. solved crystal structures; L.V.Z. analyzed the structure data; L.I.B. and V.N.Z. performed measurements of conductivity and anisotropy of conductivity; A.V.K. performed measurements on SQUID magnetometer; D.V.S. recorded EPR spectra and analyzed data; Y.N.S. supervised magnetic and resonance measurements, analyzed data and wrote the paper together with L.V.Z. and E.B.Y.; E.B.Y. supervised overall work and organized the project.

Conflicts of Interest: The authors declare no conflict of interest. The founding sponsors had no role in the design of the study; in the collection, analyses, or interpretation of data; in the writing of the manuscript, and in the decision to publish the results.

\section{References}

1. Sugawara, T. and Miyazaki, A. Magnetism and Conductivity. In Multifunctional Molecular Materials; Ouahab, L., Ed.; Pan Stanford Publishing, Pte. Ltd.: Singapore, 2013; pp. 1-60.

2. Coronado, E.; Day, P. Magnetic molecular conductors. Chem. Rev. 2004, 104, 5419-5449. [CrossRef] [PubMed]

3. Kobayashi, H.; Cui, H.; Kobayashi, A. Organic Metals and Superconductors Based on BETS (BETS = Bis(ethylenedithio)tetraselenafulvalene). Chem. Rev. 2004, 104, 5265-5288. [CrossRef] [PubMed]

4. Enoki, T.; Miyazaki, A. Magnetic TTF-based charge-transfer complexes. Chem. Rev. 2004, 104, 5449-5477. [CrossRef] [PubMed]

5. Kushch, N.D.; Yagubskii, E.B.; Kartsovnik, M.V.; Buravov, L.I.; Dubrovskii, A.D.; Biberacher, W. Pi-donor BETS based bifunctional superconductor with polymeric dicyanamidomanganate(II) anion layer: к-(BETS $)_{2} \mathrm{Mn}\left[\mathrm{N}(\mathrm{CN})_{2}\right]_{3}$. J. Am. Chem. Soc. 2008, 130, 7238-7240. [CrossRef] [PubMed]

6. Vyaselev, O.M.; Kartsovnik, M.V.; Biberacher, W.; Zorina, L.V.; Kushch, N.D.; Yagubskii, E.B. Magnetic transformations in the organic conductor $\mathrm{k}-(\mathrm{BETS})_{2} \mathrm{Mn}\left[\mathrm{N}(\mathrm{CN})_{2}\right]_{3}$ at the metal-insulator transition. Phys. Rev. B 2011, 83, 094425. [CrossRef]

7. Kurmoo, M.; Graham, A.W.; Day, P.; Coles, S.J.; Hursthouse, M.B.; Caulfield, J.L.; Singleton, J.; Pratt, F.L.; Hayes, W.; Ducasse, L.; et al. Superconducting and semiconducting magnetic charge-transfer salts: (BEDT-TTF $)_{4} A \mathrm{Fe}\left(\mathrm{C}_{2} \mathrm{O}_{4}\right)_{3} \mathrm{C}_{6} \mathrm{H}_{5} \mathrm{CN}\left(A=\mathrm{H}_{2} \mathrm{O}, \mathrm{K}, \mathrm{NH}_{4}\right)$. J. Am. Chem. Soc. 1995, 117, 12209-12217. [CrossRef]

8. Rashid, S.; Turner, S.S.; Day, P.; Howard, J.A.K.; Guionneau, P.; McInnes, E.J.L.; Mabbs, F.E.; Clark, R.J.H.; Firth, S.; Biggs, T.J. New superconducting charge-transfer salts (BEDT-TTF) $\left[A \cdot M\left(\mathrm{C}_{2} \mathrm{O}_{4}\right)_{3}\right] \cdot \mathrm{C}_{6} \mathrm{H}_{5} \mathrm{NO}_{2}$ ( $A=\mathrm{H}_{3} \mathrm{O}$ or $\mathrm{NH}_{4}, M=\mathrm{Cr}$ or Fe, BEDT-TTF = bis(ethylenedithio)tetrathiafulvalene). J. Mater. Chem. 2001, 11, 2095-2101. [CrossRef]

9. Laukhin, V.N.; Audouard, A.; Fortin, J.-Y.; Vignolles, D.; Prokhorova, T.G.; Yagubskii, E.B.; Canadell, E. Quantum oscillations in coupled orbits networks of (BEDT-TTF) salts with tris(oxalato)metallate anions. Low Temp. Phys. (Fiz. Nizk. Temp.) 2017, 43, 33-40. [CrossRef]

10. Prokhorova, T.G.; Yagubskii, E.B. Organic conductors and superconductors based on bis(ethylenedithio) tetrathiafulvalene radical cation salts with supramolecular tris(oxalato)metallate anions. Russ. Chem. Rev. 2017, 86, 164-180. [CrossRef] 
11. Otsuka, T.; Kobayashi, A.; Miyamoto, Y.; Kiuchi, J.; Nakamura, S.; Wada, N.; Fujiwara, E.; Fujiwara, H.; Kobayashi, H. Organic antiferromagnetic metals exhibiting superconducting transitions $\mathrm{k}-(\mathrm{BETS})_{2} \mathrm{FeX}_{4}$ $(X=\mathrm{Cl}, \mathrm{Br})$ : Drastic effect of halogen substitution on the successive phase transitions. J. Solid State Chem. 2001, 159, 407-412. [CrossRef]

12. Ojima, E.; Fujiwara, H.; Kato, K.; Kobayashi, H.; Tanaka, H.; Kobayashi, A.; Tokumoto, M.; Cassoux, P. Antiferromagnetic organic metal exhibiting superconducting transition, $\mathrm{k}-(\mathrm{BETS})_{2} \mathrm{FeBr}_{4}[\mathrm{BETS}=$ bis(ethylenedithio)tetraselenafulvalene]. J. Am. Chem. Soc. 1999, 121, 5581-5582. [CrossRef]

13. Coronado, E.; Galan-Mascaros, J.R.; Gomez-Garcia, C.J.; Laukhin, V.N. Coexistence of ferromagnetism and metallic conductivity in a molecule-based layered compound. Nature 2000, 408, 447-449. [CrossRef] [PubMed]

14. Uji, S.; Shinagawa, H.; Terashima, T.; Yakabe, T.; Terai, Y.; Tokumoto, M.; Kobayashi, A.; Tanaka, H.; Kobayashi, H. Magnetic-field-induced superconductivity in a two-dimensional organic conductor. Nature 2001, 410, 908-910. [CrossRef] [PubMed]

15. Fujiwara, H.; Kobayashi, H.; Fujiwara, E.; Kobayashi, A. An indication of magnetic-field-induced superconductivity in a bifunctional layered organic conductor, k-(BETS) ${ }_{2} \mathrm{FeBr}_{4}$. J. Am. Chem. Soc. 2002, 124, 6816-6817. [CrossRef] [PubMed]

16. Valade, L.; Malfant, I.; Faulmann, C. Toward bifunctional materials with conducting, photochromic, and spin crossover properties. In Multifunctional Molecular Materials; Ouahab, L., Ed.; Pan Stanford Publishing, Pte. Ltd.: Singapore, 2013; pp. 149-184.

17. Sato, O.; Li, Z.-Y.; Yao, Z.-S.; Kang, S.; Kanegawa, S. Multifunctional materials combining spin-crossover with conductivity and magnetic ordering. In Spin-Crossover Materials: Properties and Applications; Halcrow, M.A., Ed.; John Wiley \& Sons: Oxford, UK, 2013; pp. 304-319.

18. Kato, R. Conducting Metal Dithiolene Complexes: Structural and Electronic Properties. Chem. Rev. 2004, 104, 5319-5346. [CrossRef] [PubMed]

19. Melby, L.R.; Harder, R.J.; Hertler, W.R.; Mahler, W.; Benson, R.E.; Mochel, W.E. Substituted Quinodimethans. II. Anion-radical Derivatives and Complexes of 7,7,8,8-Tetracyano-quinodimethan. J. Am. Chem. Soc. 1962, 84, 3374-3387. [CrossRef]

20. Schegolev, I.F. Electric and magnetic properties of linear conducting chains. Phys. Status Solidi (a) 1972, 12, 9-45. [CrossRef]

21. Shibaeva, L.; Atovmyan, O. The structure of conducting 7,7,8,8-tetracyanoquinodimethane complexes. J. Struct. Chem. 1972, 13, 514-531. [CrossRef]

22. Yagubskii, E.B. From quasi-one-dimensional conductors based on TCNQ salts to the first quasi-two-dimensional superconductors at ambient pressure based on BEDT-TTF triiodides. In Organic Conductor, Superconductors and Magnets: From Synthesis to Molecular Electronics; Ouahab, L., Yagubskii, E.B., Eds.; Kluwer Academic Publishers: Dordrecht, the Netherlands, 2003; pp. 45-65.

23. Herbstein, F.H.; Kapon, M. Classification of closed shell TCNQ salts into structural families and comparison of diffraction and spectroscopic methods of assigning charge states to TCNQ moieties. Crystallogr. Rev. 2008, 14, 3-74. [CrossRef]

24. Halcrow, M.A. (Ed.) Spin-Crossover Materials: Properties and Applications; John Wiley \& Sons: Oxford, UK, 2013.

25. Halcrow, M.A. Structure: Function relationships in molecular spin-crossover complexes. Chem. Soc. Rev. 2011, 40, 4119-4142. [CrossRef] [PubMed]

26. Nemec, I.; Herchel, R.; Salitros, I.; Travnicek, Z.; MoncoI, J.; Fuess, H.; Ruben, M.; Linert, W. Anion driven modulation of magnetic intermolecular interactions and spin crossover properties in an isomorphous series of mononuclear iron(III) complexes with a hexadentate Schiff base ligand. CrystEngComm 2012, 14, 7015-7024. [CrossRef]

27. Murata, K.; Kagoshima, S.; Yasuzuka, S.; Yoshino, H.; Kondo, R. High-Pressure Research in Organic Conductors. J. Phys. Soc. Jpn. 2006, 75, 051015. [CrossRef]

28. Yasuzuka, S.; Murata, K. Recent progress in high-pressure studies on organic conductors. Sci. Technol. Adv. Mater. 2009, 10, 024307. [CrossRef] [PubMed]

29. Takahashi, K.; Cui, H.-B.; Okano, Y.; Kobayashi, H.; Einaga, Y.; Sato, O. Electrical Conductivity Modulation Coupled to a High-Spin-Low-Spin Conversion in the Molecular System $\left[\mathrm{Fe}^{\mathrm{III}}(\mathrm{qsal})_{2}\right]\left[\mathrm{Ni}(\mathrm{dmit})_{2}\right]_{3} \cdot \mathrm{CH}_{3} \mathrm{CN} \cdot \mathrm{H}_{2} \mathrm{O}$. Inorg. Chem. 2006, 45, 5739-5741. [CrossRef] [PubMed] 
30. Takahashi, K.; Cui, H.-B.; Okano, Y.; Kobayashi, H.; Mori, H.; Tajima, H.; Einaga, Y.; Sato, O. Evidence of the Chemical Uniaxial Strain Effect on Electrical Conductivity in the Spin-Crossover Conducting Molecular System: $\left[\mathrm{Fe}^{\mathrm{III}}(\mathrm{qnal})_{2}\right]\left[\mathrm{Pd}(\mathrm{dmit})_{2}\right]_{5}$. Acetone. J. Am. Chem. Soc. 2008, 130, 6688-6689. [CrossRef] [PubMed]

31. Nihei, M.; Takahashi, N.; Nishikawa, H.; Oshio, H. Spin-crossover behavior and electrical conduction property in iron(II) complexes with tetrathiafulvalene moieties. Dalton Trans. 2011, 40, 2154-2156. [CrossRef] [PubMed]

32. Plan, H.; Benjamin, S.M.; Steven, E.; Brooks, J.S.; Shatruk, M. Photomagnetic Response in Highly Conductive Iron(II) Spin-Crossover Complexes with TCNQ Radicals. Angew. Chem. Int. Ed. 2015, 54, 823-827.

33. Zhang, X.; Wang, Z.-X.; Xie, H.; Li, M.-X.; Woods, T.J.; Dunbar, K.R. A cobalt(II) spin-crossover compound with partially charged TCNQ radicals and an anomalous conducting behavior. Chem. Sci. 2016, 7, 1569-1574. [CrossRef]

34. Dorbes, S.; Valade, L.; Real, J.A.; Faulmann, C. [Fe(sal 2 -trien)][Ni(dmit) 2 ]: Towards switchable spin crossover molecular conductors. Chem. Commun. 2005, 69-71. [CrossRef] [PubMed]

35. Faulmann, C.; Dorbes, S.; Real, J.A.; Valade, L. Electrical conductivity and spin crossover: Towards the first achievement with a metal bis dithiolene complex. J. Low Temp. Phys. 2006, 142, 261-266. [CrossRef]

36. Faulmann, C.; Dorbes, S.; Garreau de Bonneval, B.; Molnar, G.; Bousseksou, A.; Gomes-Garcia, C.J.; Coronado, E.; Valade, L. Towards molecular conductors with a spin-crossover phenomenon: Crystal structures, magnetic properties and Mossbauer spectra of [Fe(salten)Mepepy][M(dmit $\left.)_{2}\right]$ complexes. Eur. J. Inorg. Chem. 2005, 2005, 3261-3270. [CrossRef]

37. Faulmann, C.; Jacob, K.; Dorbes, S.; Lampert, S.; Malfant, I.; Doublet, M.-L.; Valade, L.; Real, J.A. Electrical conductivity and spin crossover: A new achievement with a metal bis dithiolene complex. Inorg. Chem. 2007, 46, 8548-8559. [CrossRef] [PubMed]

38. Fukuroi, K.; Takahashi, K.; Mochida, T.; Sakurai, T.; Ohta, H.; Yamamoto, T.; Einada, Y.; Mori, H. Synergistic Spin Transition between Spin Crossover and Spin-Peierls-like Singlet Formation in the Halogen-Bonded Molecular Hybrid System: [Fe(Iqsal $\left.)_{2}\right]\left[\mathrm{Ni}(\mathrm{dmit})_{2}\right] \cdot \mathrm{CH}_{3} \mathrm{CN} \cdot \mathrm{H}_{2} \mathrm{O}$. Angew. Chem. Int. Ed. 2014, 53, 1983-1986. [CrossRef] [PubMed]

39. Nakano, M.; Fujita, N.; Matsubayashi, G.E.; Mori, W. Modified chesnut model for spin-crossover semiconductors [Fe(acpa) 2 ](TCNQ)n. Mol. Cryst. Liq. Cryst. 2002, 379, 365-370. [CrossRef]

40. Shvachko, Y.N.; Starichenko, D.V.; Korolyov, A.V.; Yagubskii, E.B.; Kotov, A.I.; Buravov, L.I.; Lyssenko, K.A.; Zverev, V.N.; Simonov, S.V.; Zorina, L.V.; et al. The Conducting Spin-Crossover Compound Combining Fe(II) Cation Complex with TCNQ in a Fractional Reduction State. Inorg. Chem. 2016, 55, 9121-9130. [CrossRef] [PubMed]

41. Kistenmacher, T.J.; Emge, T.J.; Bloch, A.N.; Cowan, D.O. Structure of the red, semiconducting form of 4,4',5,5'-tetramethyl- $\Delta 2,2^{\prime}$-bi-1,3-diselenole-7,7,8,8-tetracyano-p-quinodimethane, TMTSF-TCNQ. Acta Cryst. B 1982, 38, 1193-1199. [CrossRef]

42. Radváková, A.; Kazheva, O.N.; Chekhlov, A.N.; Dyachenko, O.A.; Kucmin, M.; Kajňaková, M.; Feher, A.; Starodub, V.A. Two-gap magnetic structure of the two-stack anion-radical salt (N-Me-3,5-Di-Me-Py)(TCNQ) 2 (Py is pyridine). J. Phys. Chem. Solids 2010, 71, 752-757. [CrossRef]

43. Pukacki, W.; Graja, A. Electric and magnetic properties of organometallic TCNQ salts. Synth. Met. 1988, 24, 137-143. [CrossRef]

44. Petersen, R.L.; Symons, M.C.R.; Taiwo, F.A. Application of radiation and ESR spectroscopy to the study of ferryl haemoglobin. J. Chem. Soc. Faraday Trans. 1 1989, 85, 2435-2444. [CrossRef]

45. Pilbrow, J.R. Transition Ion Electron Paramagnetic Resonance; Clarendon Press: Oxford, UK, 1990.

46. Hagen, W.R. Biomolecular EPR Spectroscopy; CRC Press: Boca Raton, FL, USA, 2009.

47. Weil, J.A.; Wertz, J.E.; Bolton, J.R. Electron Paramagnetic Resonance: Elementary Theory and Practical Applications; John Wiley: New York, NY, USA, 1994.

48. Paradis, N.; Le Gac, F.; Guionneau, P.; Largeteau, A.; Yufit, D.S.; Rosa, P.; Létard, J.-F.; Chastanet, G. Effects of Internal and External Pressure on the [Fe(PM-PEA) $\left.)_{2}(\mathrm{NCS})_{2}\right]$ Spin-Crossover Compound (with PM-PEA=N-(21-pyridylmethylene)-4(phenylethynyl)aniline). Magnetochemistry 2016, 2, 15-32. [CrossRef]

49. Barnes, S.E. Theory of electron spin resonance of magnetic ions in metals. Adv. Phys. 1981, 30, 801-938. [CrossRef]

50. Kürti, J.; Menczel, G. g-Factor anisotropy and charge transfer in three complex TCNQ salts. Phys. Status Solidi B 1980, 102, 639-645. [CrossRef] 
51. Brooker, S. Spin crossover with thermal hysteresis: Practicalities and lessons learnt. Chem. Soc. Rev. 2014, 44, 2880-2892. [CrossRef] [PubMed]

52. Benelli, C.; Gatteschi, D. Introduction to Molecular Magnetism: From Transition Metals to Lanthanides; Wiley-VCH: Weinheim, Germany, 2015.

53. Létard, J.-F.; Guionneau, P.; Rabardel, L.; Howard, J.A.K.; Goeta, A.E.; Chasseau, D.; Kahn, O. Structural, Magnetic, and Photomagnetic Studies of a Mononuclear Iron(II) Derivative Exhibiting an Exceptionally Abrupt Spin Transition. Light-Induced Thermal Hysteresis Phenomenon. Inorg. Chem. 1998, 37, 4432-4441. [CrossRef] [PubMed]

54. Day, P.; Underhill, A.E. Metal-organic and Organic Molecular Magnets. Phil. Trans. R. Soc. Lond. A 1999, 357, 2849-3184.

55. Starodub, V.A.; Starodub, T.N. Radical anion salts and charge transfer complexes based on tetracyanoquinodimethane and other strong $\pi$-electron acceptors. Russ. Chem. Rev. 2014, 83, 391-438. [CrossRef]

56. Zhao, H.; Heintz, R.A.; Ouyang, X.; Grandinetti, G.; Cowen, J.; Dunbar, K.R. Insight into the Behavior of $\mathrm{M}(\mathrm{TCNQ}) n(n=1,2)$ Crystalline Solids and Films: X-ray, Magnetic and Conducting Properties. NATO ASI: Supramolecular Engineering of Synthetic Metallic Materials: Conductors and Magnets; Veciana, J., Ed.; Kluwer: Dordrecht, The Netherlands, 1999; Volume 518, pp. 353-376.

57. Clerac, R.; O’Kane, S.; Cowen, J.; Ouyang, X.; Heintz, R.A.; Zhao, H.; Bazile, M.J., Jr.; Dunbar, K.R. Glassy Magnets Composed of Metals Coordinated to 7,7,8,8-tetracyanoquinodimethane: $M(\mathrm{TCNQ})_{2}(M=\mathrm{Mn}, \mathrm{Fe}$, Co, Ni). Chem. Mater. 2003, 15, 1840-1850. [CrossRef]

58. Nweedle, M.F.; Wilson, L.J. Variable spin iron(III) chelates with hexadentate ligands derived from triethylenetetramine and various salicylaldehydes. Synthesis, characterization, and solution state studies of a new ${ }^{2} \mathrm{~T} \leftrightarrow{ }^{6} \mathrm{~A}$ spin equilibrium system. J. Am. Chem. Soc. 1976, 98, 4824-4834.

59. Sheldrick, G.M. A short history of SHELX. Acta Cryst. A 2008, 64, 112-122. [CrossRef] [PubMed]

60. Montgomery, H.C. Method for Measuring Electrical Resistivity of Anisotropic Materials. J. Appl. Phys. 1971, 42, 2971. [CrossRef]

61. Buravov, L.I. Calculation of resistance anisotropy with regard to model ends by conformal-transformation. Zhurnal Tekh. Fiz. 1989, 59, 138-142. 